OBETS. Revista de Ciencias Sociales

Vol. 16, no 2, 2021, pp. 393-416

ISSN: 1989-1385

https://doi.org/10.14198/OBETS2021.16.2.11

\title{
LA EMANCIPACIÓN DE LOS JÓVENES DESDE LOS CENTROS DE PROTECCIÓN DE MENORES: LA VISIÓN PROFESIONAL
}

\author{
THE EMANCIPATION OF YOUNG PEOPLE IN CHILD PROTECTION CENTRES: \\ THE PROFESSIONAL PERSPECTIVE
}

\author{
Isabel Martínez Salvador \\ Universidad de Almería, España \\ isabelmartinez@ual.es \\ https://orcid.org/0000-0001-8859-5309 \\ Jesús Muyor Rodríguez \\ Universidad de Almería. CEMyRI, España \\ jesusmuyor@ual.es \\ https://orcid.org/0000-0003-4226-5181
}

Rocío López San Luís

Universidad de Almería, España

rlopez@ual.es

https://orcid.org/0000-0002-6356-2591

\begin{abstract}
Cómo citar / Citation: Martínez, I.; Muyor, J. y López, R. (2021) "La emancipación de los jóvenes desde los centros de protección de menores: La visión profesional”. OBETS. Revista de Ciencias Sociales, 16(2): 393-416. https://doi.org/10.14198/OBETS2021.16.2.11
\end{abstract}

C 2021 Isabel Martínez Salvador, Jesús Muyor Rodríguez, Rocío López San Luís

Este es un artículo de acceso abierto distribuido bajo los términos de la licencia de uso y distribución Creative Commons Reconocimiento 4.0 Internacional (CC BY 4.0) https://creativecommons.org/licenses/by/4.0/deed.es

Recibido: 19/05/20. Aceptado: 31/12/20

\section{Resumen}

En este artículo se analiza la transición hacia la vida adulta del colectivo de menores tutelados en el sistema de protección español. Desde un enfoque cualitativo, utilizamos la entrevista semiestructurada como técnica de investigación. Se realizan 30 entrevistas a profesionales que trabajan en centros de protección de menores en la zona de Andalucía oriental. Los profesionales reflejan una ruptura entre las expectativas de los menores al iniciar su proyecto migratorio, las vivencias en los centros de protección y el alto riesgo social que supone el tránsito hacia la mayoría de edad.

Palabras Clave: Menores migrantes; no acompañados; protección de menores; jóvenes tutelados; acogimiento residencial, emancipación; vida adulta.

\begin{abstract}
This article analyses the transition to adult life of the unaccompanied minors in care in the Spanish child protection system. From a qualitative approach, we use the semi-structured interview as a research technique. Thirty interviews were conducted with professionals working in child protection centres in eastern Andalusia. The professionals reveal the differences between the expectations of the minors who start their migratory journey and the reality of their experiences in the protection centres and the high level of social risk that the transition to adulthood implies.
\end{abstract}

Keywords: Migrant minors; unaccompanied minors; protection of minors; young people in care; residential care, emancipation; adult life. 


\section{Extended abstract}

The transition to adulthood of adolescents who are living in protective care has not been a priority issue for Spanish public policy. The transition to independent adult life for these young people is not yet seen as an extension of the protective measures currently provided by the State. There is no specific regulation on how to deal with the emancipation of young people in protective care (Del Valle, 2008).

At the academic level, research on the transition to independent living, as well as its consequences for the adolescents emancipated from protection systems, had not been developed until the late 1990s (Del Valle, 1998).

In recent years there has been greater interest in research on the most relevant aspects of the transition to adult independence of young people in care. The scientific evidence shows that adolescents who have been emancipated and especially those in protection centres face many difficulties when starting their independent lives. The principal reasons for these include low academic achievement, precarious employment and lack of adequate information about their legal situation, rights and obligations (Durán, 2019; Nicolae, 2019; Ortega, 2019).

López, Santos, Bravo \& Del Valle (2013) warn that when minors in protective care reach the age of majority, they automatically cease to be protected by the public authorities and begin a forced and accelerated process of independence. This phase, characterised by a lack of protection from the public authorities becomes particularly relevant given the generalized and extensive personal and socioeconomic profile of foreign minors in care.

As indicated by Jiménez (2003), since 1995, a new migratory phenomenon has become manifest in Spain, characterized by minors who undertake their migratory journey without their parents, siblings or the care of some other adult. This group is popularly known as Unaccompanied Foreign Minors (In Spanish, MENA(s), which stands for Menores Extranjeros no Acompañados). This group is in a particularly vulnerable situation because they are doubly unprotected. On the one hand, they are minors and, on the other, they are undertaking the migration journey alone, without the company or protection of an adult (Peláez, 2018).

The institutional network for the protection of unaccompanied immigrant minors consists of initial reception centres and basic residential centres that provide accommodation until they reach the age of majority. At present, there are a large number of young people who have reached the age of 18 and must leave these centres. For these young people, who have reached the age of majority and, who up till that time had been cared for by public authorities, in Andalusia, two types of care are made available to them. These are structured as follows: permanent care in High Intensity resources, and day centres considered to be of Medium Intensity. In some cases, these actions can be extended to the age of twenty-five.

However, in practice, there is evidence of the scarce resources being uniformly supplemented by other means. Professionals denounce the tensions and difficulties that arise from the growing demand, the weakening of the structure of institutional protection and the internal factors that mediate the actual social and educational interventions in the protection centres for minors (APDHA, 2006; Save the Children, 2018; Andalucía Acoge, 2019).

In view of the aforementioned, in this paper we carry out a holistic exploration of the characteristics of the process whereby minors in care transition towards adulthood and their exit from the protection system. We focus on the experts' perspective, with the aim of evincing, from the situated knowledge of professional practice, the controversies between the institutional protective actions and the needs, demands and expectations that the minors relate to the professionals working in the protection centres.

\section{Methodology}

The objective is to analyze the vision of professional teams on the process of transition to the coming of age of unaccompanied foreign minors. Specifically, we want to highlight the most significant issues, the data that emerge, that are prioritized and emphasized.

Our research has been carried out from a qualitative methodological approach and is based on the research technique of semi-structured interviews (Taylor \& Bogdan, 2010). The method combines ethnography and Grounded Theory.

The instrument used for information collection consisted of a script composed of 25 open-ended items, where the order of questions begins with more general questions and concludes with a more in-depth analysis of particular aspects.

The study was carried out using non-probabilistic intentional sampling. It is based on the intentionality that the researchers have decided upon to form the components of the sample as these are considered to be key to the objectives of the study (Ruiz, 2012). The inclusion criteria of the participants are determined by the fact that they are professionals actively working in child protection centres. The characteristics of the subjects are mainly adjusted according to the varying nature of the protection centres (Initial Reception, Basic Residential Care and High Intensity Care).

We have obtained a total sample of 30 participants from seven different centres for the protection of minors in the province of Almeria. It is assumed that the sample obtained encompasses the positions and opinions of the experts and have attained an acceptable degree of saturation in the responses.

The information collection process is carried out individually, in places in which the interviewees felt comfortable.

The average time of the interviews is 01:23 (hh:mm), which were conducted without incident or significant interruptions.

The information analysis process was carried out using ATLAS.ti software.

An inductive coding was carried out that allowed us to code the ideas and/or concepts, to categorise the information by means of codes that concentrated on dimensions or subcategories, and which in turn, were grouped into other major or central analytical categories. 


\section{Results and Conclusions}

The migration trajectory of minors is carried out with the main purpose of improving the family situation in their country of origin. This migratory stimulus is based on the central idea that the minors in care wish to access stable employment, which itself is an instrument to structure their life plan. However, the expectations of young people, aside from their view of employment being the central axis of their expectations and life plans, often do not match reality. There is evidence of an idealization of Spain as an opportunity to improve the situation of these young people and their families which contributes to reinforcing the "European dream". Consequently, the professionals propose a practical approach based on making minors aware of the reality of their situation. The practitioners show their minors, in person and realistic settings, the situations of vulnerability, precariousness and exclusion in which many adult immigrants who arrive in Spain in similar conditions live. With this approach, the professional team seeks to minimize the distortion between the expectations of the minors and the realistic goals that can be defined.

Regarding the transition to adult life, foreign minors in protective care share the idea that leaving the system makes them feel insecurity, loneliness and, above all, of a lack of support. Professionals report that there is a total lack of protection from the system when the minors turn 18 . Awareness of this on the part of the minors has a negative impact on their educational plans, attitudes and behaviour, as well as on reconfiguring their future. The future helplessness of the young people who have been released from protective care provides opportunities for personal development of these young people, even if they had previously been in protective care. As minors approach adulthood, more disruptive behaviours and negative psychological expressions become visible. Hence the need to prevent possible risks. The possibility for these young people to be guaranteed protective cover at the legal level (administrative situation), social level (resources after coming of age) and economic level (through the guarantee of unconditional income) constitute, in themselves, mechanisms of risk prevention and intervention of the minors in care.

We also point out that professionals have an ethnocentric discourse of reality. The Western and European social system is not questioned, but is used as a framework for the integration of minors. On the contrary, the culture of minors is perceived as a difficulty to achieve integration.

The future projection of high social risk that professionals warn about for young people who have released from protective care justifies the need to question the model of protection of minors in care; in addition to acting rigorously in the face of the evidence offered by professional experience. This research offers new evidence that shows the future challenges that still need to be addressed. The results obtained in this study can serve as a guide towards the redesign of policies for the protection of minors in care from the expert perspective of the professionals who work directly with this group.

\section{INTRODUCCIÓN}

La transición hacia la vida adulta de los adolescentes que se encuentran bajo medidas de protección no ha sido un tema prioritario en las políticas públicas españolas. El tránsito hacia la vida independiente de estos jóvenes aún no se contempla como prolongación de la actividad protectora que ejerce el Estado. No existe una regulación específica de cómo afrontar la emancipación de los jóvenes que están bajo medidas de protección (Del Valle, 2008).

A nivel académico, las investigaciones sobre la transición a la vida independiente, así como sus consecuencias en aquellos adolescentes emancipados de los sistemas de protección, no se desarrollan hasta la última etapa de los años noventa (Del valle, 1998). Estas investigaciones fueron ampliadas años más tarde por el propio Del Valle (2006) y otros autores como Inglés, (2005), García-Barriocanal, Imaña \& De la Herrán, (2007), Melendro (2007) y Casas \& Montserrat (2009).
En los últimos años existe un mayor interés por la investigación sobre los aspectos más relevantes en la etapa de transición a la vida independiente de los jóvenes tutelados. Cada vez son más los estudios realizados sobre planes de actuación de carácter formativo para la preparación hacia la emancipación de estos jóvenes (Jariot, Parrón, Roca \& Villalba, 2008). También, se han llevado a cabo estudios para analizar el proceso educativo y la inserción en el mercado laboral (Sala-Roca, Villalba, Jariot \& Rodríguez, 2009; Casas, Malo \& Bertran, 2011). Además, del estudio sobre procesos de socialización y redes sociales (Sala-Roca, Villalba, Jariot \& Arnau, 2012).

Otros autores, como Campos (2013), abordan sus trabajos desde una perspectiva más global. La línea de investigación desarrollada cuenta con referencias concretas a las estrategias y los procesos de intervención socioeducativa que se desarrollan con los adolescentes emancipados. Desde este enfoque, se relacionan aspectos contextuales de tipo institucional, familiar y socioeconómico con una serie de descriptores básicos 
sobre su situación adulta y el grado de inserción social logrado.

López, Santos, Bravo \& Del Valle (2013) alertan que a los menores tutelados se les cesa automáticamente la medida protectora al cumplir la mayoría de edad. A partir de ahí, comienzan un proceso de independencia forzoso y acelerado que está caracterizado por una evidente desprotección pública. El perfil generalizado y extendido de menores extranjeros tutelados otorga una relevancia significativa al tránsito hacia la mayoría de edad.

Tal y como señala Jiménez (2003), es a partir del año 1995 cuando comienza a darse en nuestro país un nuevo fenómeno migratorio. Estas migraciones están protagonizadas por menores que realizan el proceso sin el acompañamiento de sus progenitores, hermanos o algún adulto que ejerza como responsable de su cuidado. Quiroga (2003), en su tesis doctoral, contextualiza cómo fue el proceso de toma de conciencia del fenómeno que se vivió a finales de los años 90 en Barcelona. La investigadora señala el gran desconocimiento que existía sobre esta realidad. La visible demanda y la presión de la opinión pública motivaron la creación de nuevos centros. Sin embargo, estos recursos se implementaron con una escasa planificación y eficacia. Estas primeras respuestas estaban caracterizadas por la atención a las urgencias de los menores en situación de calle. Las medidas desarrolladas no se ajustaban a las necesidades más globales y a las expectativas migratorias de los menores.

Este colectivo ha sido denominado, popularmente, como Menores Extranjeros No Acompañados (MENA en su versión individualizada y MENAS en plural). Este término es el más utilizado por los profesionales, medios de comunicación y sociedad en general. Además, se emplean otros como MINA (Menores Inmigrantes No Acompañados), MNA (Menores No Acompañados), MEINA (Menores Extranjeros Indocumentados No Acompañados). Si bien, existe una corriente más crítica con estos términos que sugieren su reemplazo por otros como Menores migrantes sin referentes familiares en la sociedad receptora (Bargach, 2009), menores que migran de forma autónoma (Jiménez, 2011) o movilidades infantiles autónomas (Montesino, 2015).

El fenómeno de los menores extranjeros no acompañados ha estado caracterizado por la intersección de la condición de minoría de edad y la categorización de (in)migrante. Por un lado, son menores de edad y, por otro, se ven inmersos en un proceso migratorio (Peláez, 2018). Estas cuestiones han generado complejidades jurídicas y tensiones que impactan en la propia acción protectora (Aparicio, 2015). La aplicación de los derechos de los menores, en función del interés superior del menor, también encuentra resistencias ejercidas por la presión de la política migratoria que está fuertemente articulada a las concepciones de seguridad y represión de la inmigración en situación irregular (Durán, 2019). Al respecto, las entidades organizativas y asociativas han denunciado, reiteradamente, su preocupación por considerar que, en el sistema de protección y en el sistema jurídico, prevalece la condición de migrante sobre la de menor de edad (APDHA, 2006; Save the Children, 2018; Andalucía Acoge, 2019).

Según la última memoria anual publicada por la Fiscalía General del Estado (2019), en 2018 han sido localizados 7.026 menores extranjeros no acompañados llegados a España por vía marítima en pateras u otras embarcaciones frágiles; dato muy significativo si además se compara con los menores acompañados que han llegado por la misma vía. Estos últimos son un total de 755 menores en unión de adultos (menores acompañados), que afirmaban tener vínculo paternomaterno filial con el niño sin acreditarlo de manera fehaciente.

El dato de menores no acompañados de 2018 representa un incremento de un 199,61\% con relación al año 2017 (2.345 menores) y de un $3.050 \%$ respecto al número de menores que llegaron por esta misma vía en el año 2014 (223 menores).

El 96,9\% (6.810) son de sexo masculino y el resto (216) son niñas menores. Mayoritariamente proceden de Marruecos (61,89\%), República de Guinea $(14,10 \%)$, Mali (8,15\%), Argelia (5,6\%), Costa de Marfil (4.5\%) y Gambia (1.69\%), seguidos por otros países principalmente del África Subsahariana. También se localizó un menor de Arabia Saudí, otro de la India y trece de Bangladesh.

En este contexto, es importante señalar que existe una población de menores no acompañados no cuantificada, ya que no se ha considerado el número de los menores que se han introducido en España a través de Ceuta y Melilla. 
Siguiendo con los datos proporcionados por la Fiscalía, en el Registro de Menores Extranjeros No Acompañados figuraban inscritos, a fecha de 31 de diciembre de 2018, un total de 13.796 menores bajo la tutela o acogimiento de los servicios de protección. De ellos, 12.825 son niños y 971 niñas. Esto supone un incremento de un $115 \%$ respecto de los 6.414 inscritos en el año 2017. La mayoría se encuentran tutelados por la Comunidad Andaluza (6.294 menores); 1842 se encuentran en Cataluña; 1.322 en Melilla; 990 en el País Vasco; 730 en la Comunidad valenciana; 553 en Ceuta; 490 en Madrid; 390 en Murcia; 281 en Canarias; 175 en Aragón; 160 en Castilla-La Mancha; 113 en Galicia; 111 en Cantabria; 103 en Asturias; 102 en Castilla y León; 64 en Baleares; 58 en Navarra; 16 en Extremadura y uno en La Rioja.

Entre los rasgos distintivos que esbozan un perfil de estos menores en España, se pueden destacar (Nicolae, 2019):

- Marruecos es la procedencia principal.

- La mayoría son varones.

- En general, vivían con su familia en el país de origen.

- Las circunstancias socio familiares son precarias.

- Frecuentemente, el nivel de estudios formal es bajo.

- No conocen el idioma español.

- El viaje migratorio está organizado. Las vías más utilizadas suelen ser por carretera y por mar. En el primer caso, se desplazan en los bajos de un camión o de un autocar. En el segundo caso, el trayecto se realiza en pateras o embarcaciones similares.

En España, las Comunidades Autónomas tienen asignadas las responsabilidades de evaluar la situación de desamparo de un menor y de adoptar las medidas de protección necesarias (Cabedo \& Cloquell, 2012). La red institucional de protección de menores inmigrantes no acompañados, a pesar de la descentralización administrativa de competencias, guarda una estructura común en todo el territorio español (Gimeno, 2018). En primer lugar, se encuentran los centros de primera acogida, o acogida inmediata, que se organizan para una primera atención, la realización del diagnóstico de su situación y el diseño de medidas para su protección. En segundo lugar, cuando se tiene el diagnóstico completo de los menores, se les asigna una plaza en un recurso residencial básico. Estos programas de atención residencial tienen como objetivo la atención integral de las necesidades de los menores, que se extienden hasta cumplir la mayoría de edad. Algunos servicios de Acogimiento Residencial ofrecen un programa específico, para menores con edades comprendidas entre los 16 y 18 años, enfocado a la orientación sociolaboral. Sin embargo, estos centros suelen ser muy escasos y su funcionamiento se orienta, con frecuencia, a otro tipo de atenciones básicas y urgentes que no son tan específicas como las actividades sociolaborales y de preparación para la vida adulta (Ortega, 2019).

En la actualidad, nos encontramos con un gran número de jóvenes que cumplen los 18 años y deben abandonar los centros de protección de menores. Para estos jóvenes mayores de edad que han sido tutelados, en Andalucía se desarrolla el "El programa + 18. La atención ante la mayoría de edad" $(\mathrm{P}+18)$. En algunos casos estas acciones se pueden prolongar hasta los veinticinco años.

En Andalucía existen dos modalidades de recursos para el Programa +18 . En primer lugar, están los recursos de Alta Intensidad que los conforman los pisos de autonomía. En ellos se ofrece una atención integral con el objetivo de satisfacer las necesidades básicas de aquellos jóvenes que han tenido que abandonar los centros de menores y carecen de cualquier posibilidad para vivir de forma autónoma. En segundo lugar, están los recursos de Media Intensidad. Estos recursos se componen de una red de centros de día donde se llevan a cabo todas las actuaciones programadas con un seguimiento constante. Este apoyo se materializa mediante numerosas acciones, entre las que destacan el acompañamiento en su proceso de autonomía plena, la formación integral no formal, becas para su formación y alquiler de una vivienda (Junta de Andalucía, 2020).

No obstante, la práctica evidencia una implementación uniforme y subsidiaria de estos recursos. Las organizaciones sociales denuncian las tensiones y dificultades que se están originando por el volumen creciente de la demanda, el debilitamiento de la estructura de protección institucional y los factores internos que mediatizan la propia intervención socioeducativa en los centros de menores. Se denuncia explícitamente la falta de implicación y de previsión de políticas acordes a las necesidades manifiestas, la desprotección de la infancia en los procedimientos de determinación de la edad, la indefensión jurídica 
y administrativa, las condiciones de saturación de los centros y la falta de recursos, así como la preocupante situación que vive la infancia migrante al cumplir la mayoría de edad (APDHA, 2019).

La evidencia científica constata que los adolescentes extutelados que se emancipan, y especialmente los tutelados en centros de protección, se encuentran con múltiples dificultades a la hora de iniciar su vida de forma independiente. Destacan, fundamentalmente, el bajo nivel académico, la precariedad laboral y la falta de información adecuada sobre cuál es su situación legal, sus derechos y obligaciones (Ortega, 2019).

En este contexto, se manifiesta la necesidad de explorar, desde múltiples perspectivas, los procesos migratorios en menores y jóvenes extranjeros no acompañados y su vinculación con los proyectos de emancipación en el colectivo de extutelados.

Con la finalidad de aproximarnos a este fenómeno, desarrollamos una investigación orientada a analizar los procesos de emancipación que realizan los menores inmigrantes desde distintos servicios de protección de la red pública de Andalucía ${ }^{1}$. Este estudio comprende dimensiones políticas, institucionales y prácticas. Para ello, se cuenta con informantes de distintos perfiles entre los que se encuentra el propio grupo de jóvenes (ex)tutelados.

Por cuestiones de extensión, estructura y pertinencia, en el artículo que presentamos nos centramos en los significados generados desde la práctica profesional. Para ello, recogemos los discursos profesionales con el objetivo de evidenciar cómo proyectan las vivencias relacionadas con las situaciones de emancipación de los menores extranjeros no acompañados que son tutelados. Queremos realizar una exploración holística de las principales características que identifican los profesionales sobre el proceso de transición hacia la mayoría de edad de estos jóvenes.

Nos interesa recoger la opinión experta en tanto que expresa no solo cómo los profesionales describen la realidad, sino cómo la construyen (Vasilachis, 2009). En este sentido, la investigación se sustenta en la reflexividad de los profesionales para dar cuenta de su acción y de los efectos de la misma en los procesos

1 Este trabajo ha recibido el apoyo económico de la Universidad de Almería. de emancipación de los jóvenes (ex)tutelados. Esta reflexividad nos ofrece la posibilidad de visibilizar la manera que adoptan los profesionales para (re)conocer los sujetos de su intervención profesional.

\section{METODOLOGÍA}

En este apartado abordamos, en primer lugar, los objetivos planteados en la investigación. Posteriormente, profundizamos en el enfoque utilizado y las perspectivas teórico-metodológicas desarrolladas. Seguidamente, abordamos un bloque de "técnicas e instrumentos" en el que se justifica la pertinencia de la utilización de la entrevista, así como la explicación sobre el instrumento utilizado. En un siguiente subapartado nos centramos en el "contexto de estudio y participantes". Se mencionan las características principales que componen el contexto de estudio y, a continuación, se señala el tipo de muestreo utilizado, la manera de selección e identificación de los participantes y la configuración final de la muestra. En el último bloque del apartado metodológico desglosamos el procedimiento para la recogida de información, así como las características principales de la fase analítica.

\subsection{Objetivos y Método}

El presente trabajo se encuadra en una aproximación situada, desde los servicios de protección de menores de la provincia de Almería, sobre la implementación de los programas que se llevan a cabo y las medidas para la preparación de la vida independiente. Nuestro objetivo es analizar la visión de los equipos profesionales sobre el proceso de transición hacia la mayoría de edad de los menores extranjeros no acompañados. Concretamente, queremos evidenciar los temas más significativos, los datos que emergen, que se priorizan y se enfatizan. Entendemos que la visibilización de estos hechos nos aproximan a la forma de actuar y (re)definir el fenómeno.

Para ello, nuestra investigación se ha llevado a cabo desde un enfoque metodológico de tipo cualitativo. La investigación cualitativa nos permite indagar la realidad en su entorno natural, ilustrando los acontecimientos conforme con las percepciones que tienen los sujetos implicados (Taylor \& Bogdan, 2010). Para establecer la postura metodológica de la investigación nos servimos de los postulados desarrollados por Valles (2009). El 
autor advierte de la necesaria complementariedad de paradigmas y perspectivas teórico-metodológicas a la hora de caracterizar la investigación cualitativa. En este sentido, hablamos de estrategia para referirnos a la influencia y utilización de los métodos que se entrelazan y convergen en el desarrollo de este trabajo.

La estrategia utilizada en este trabajo combina el método etnográfico para tomar decisiones sobre cómo abordar el objeto de estudio y la teoría fundamentada para establecer los procesos analíticos. El abordaje etnográfico está presente en esta investigación, fundamentalmente, en los elementos de "reflexividad" y la importancia del "campo" (Ameigeiras, 2009). Por un lado, la consideración de la reflexividad se plantea en el proceso de comprensión, descripción y explicación del problema de investigación. Por otro, la importancia del "campo" radica no solo en la posibilidad de observar e interpretar a los actores en su propio contexto, sino de participar en múltiples realidades desde donde despliegan su vida cotidiana. En esta línea, el trabajo desarrollado deviene de los distintos lugares de enunciación para la comprensión hermenéutica (entre otros, ámbito profesional, académico y activista).

Vinculado con el abordaje etnográfico, la estrategia propuesta utiliza el método de comparación constante y el muestreo teórico para el proceso analítico. Con ello, en un sentido amplio, se desarrollan las inferencias del estudio con arreglo a la formulación de la Teoría Fundamentada (Strauss \& Corbin, 2012).

\subsection{Técnicas e instrumentos}

Utilizamos la entrevista semiestructurada como técnica de investigación en el desarrollo del trabajo de campo. La entrevista supone un encuentro cara a cara entre la persona investigadora y los informantes respecto a sus propias experiencias y situaciones (Taylor $\&$ Bogdan, 2010). La utilización de esta técnica nos permite visibilizar y comprender los significados que los profesionales otorgan al colectivo de jóvenes tutelados en su proceso de incorporación al mundo adulto.

Para el diseño del instrumento se realizó una adaptación del guion utilizado en el estudio de Campos (2013). Para ajustar el instrumento a los objetivos de la investigación se reformularon las preguntas $y$ se añadieron nuevos ítems. Posteriormente, y con el fin de valorar el contenido del guion de la entrevista, se optó por la validación mediante el juicio de expertos. Dos profesionales cualificados en la materia expusieron sus observaciones conforme a la relevancia de los ítems, su relación con el propósito de la investigación y la comprensión de la información (Escobar \& Cuervo, 2008).

El instrumento final de recogida de información consta de un guion compuesto por 25 ítems centrales de carácter abierto, donde el orden de preguntas se inicia con cuestiones más generales hasta profundizar en aspectos particulares. La estructura de la entrevista responde a una presumible graduación en la dificultad de las respuestas. No obstante, las preguntas se contemplan de forma flexible, adaptándolas in situ al contexto del relato. Además, el orden de las preguntas se altera dependiendo del discurrir de la propia entrevista y la importancia que los informantes concedan a determinados hechos (Valles, 2009).

Tabla 1. Guion de entrevista a profesionales. Ítems centrales.

\begin{tabular}{|l|l|}
\hline Bloque 1 & $\begin{array}{l}\text { ¿Cuál crees que es la opinión de la sociedad española respecto a } \\
\text { la inmigración? ¿Cuál es la imagen que proyecta la juventud en la } \\
\text { sociedad española? ¿Consideras adecuadas las políticas públicas } \\
\text { para atender a la población inmigrante? ¿Cuáles son las políticas } \\
\text { de juventud que destacarías? }\end{array}$ \\
\hline Bloque 2 & $\begin{array}{l}\text { ¿Qué aspectos positivos y negativos encuentras en el sistema } \\
\text { de protección de menores? ¿Cómo mejorarías el sistema de } \\
\text { protección de menores? ¿Cuáles son tus funciones y actividades } \\
\text { en el centro? De acuerdo con tu experiencia, ¿Está bien } \\
\text { organizado el centro? }\end{array}$ \\
\hline Bloque 3 & $\begin{array}{l}\text { Si os consideráis como principales responsables de la educación de } \\
\text { los menores/jóvenes ¿cómo lleváis a cabo esta labor? ¿consideras } \\
\text { que hay diferencias entre los niños/as que pasan su infancia y su } \\
\text { adolescencia en el centro y los que viven con sus propias familias? } \\
\text { ¿De qué manera, desde el propio centro o desde fuera, se puede } \\
\text { satisfacer las necesidades de los menores/jóvenes? ¿Qué aspectos } \\
\text { y qué necesidades consideras necesario prestar una mayor } \\
\text { atención? ¿Consideras que en el centro donde te encuentras } \\
\text { dispones de los recursos adecuados para su atención? ¿Cómo ha } \\
\text { afectado la crisis y los recortes públicos al desempeño de vuestras } \\
\text { funciones? }\end{array}$ \\
\hline Bloque \\
final
\end{tabular}

Fuente: Elaboración propia. 
El primer bloque de la entrevista recoge preguntas de carácter más general. Los aspectos que se preguntan se vinculan con la opinión sobre la inmigración, la juventud y las políticas sociales.

En un segundo bloque se aborda la opinión de los informantes sobre el sistema de protección de menores. Son preguntas de tipo descriptivo sobre la estructura organizativa del sistema, los programas y los recursos humanos que conforman los distintos centros. Este bloque sirve para ir de la situación general del colectivo hacia las vivencias y experiencias particulares de los informantes.

En tercer lugar, se estructura una serie de preguntas que intentan explorar con mayor profundidad unidades de análisis claves para el estudio. Se abordan cuestiones como las experiencias profesionales a la hora de intervenir en los centros de protección, sus dificultades, limitaciones, cambios, propuestas de mejora.

En cuarto lugar, se pregunta sobre la experiencia de los propios menores en el centro. Se busca la proyección del sentir de los menores tutelados verbalizada por los expertos. Las áreas de exploración se centran en el proceso migratorio de los menores, la acogida en el centro, los deseos proyectados, y sobre el proceso de tutela y tránsito hacia la mayoría de edad.

En último lugar, se agrupan las preguntas que requieren de un análisis y reflexión fundamentada de los informantes. En esta fase se pregunta sobre la propia labor que realizan como profesionales, y el impacto que podría tener su actuación en la vida de los menores extutelados. Se solicita a los informantes que hagan una proyección sobre la vida de los menores una vez abandonen el recurso de protección.

Se deja una fase de cierre para que el informante pregunte sobre aquellas cuestiones de la entrevista que considere oportuno.

\subsection{Contexto de estudio y participantes}

Para contextualizar el estudio, es importante señalar que, pese a la deficiencia de los datos oficiales, a la provincia de Almería se le asigna el tercer puesto en acogida de menores extranjeros no acompañados en Andalucía. La proximidad con el norte de África, el corredor del Mediterráneo como vía hacia el centro de Europa y la actividad económica, basada en la agricultura, juegan un papel determinante en esta situación (Defensor del Menor de Andalucía, 2020).
Para identificar la red pública de protección de menores y jóvenes extranjeros no acompañados en la provincia de Almería, se solicitó un informe a la Delegación Territorial de Educación, Deporte, Igualdad, Políticas Sociales y Conciliación.

Con el fin de mantener el anonimato de las entidades y preservar la información de la distribución de sus centros, se presenta una tabla organizada exclusivamente según el número de plazas asignadas a cada programa. Para referirnos a las entidades utilizaremos una codificación de caracteres alfabéticos.

Tabla 3. Entidades y número de plazas asignadas a cada programa de la red de protección de menores y jóvenes (ex) tutelados en la provincia de Almería. Mayo 2020.

\begin{tabular}{|c|c|c|}
\hline \multicolumn{3}{|c|}{ GESTIÓN PÚBLICA } \\
\hline ENTIDAD & PROGRAMA & PLAZAS \\
\hline A & Acogida Inmediata & 35 \\
\hline B & Acogida inmediata & 18 \\
\hline \multicolumn{3}{|c|}{ GESTIÓN PRIVADA } \\
\hline ENTIDAD & PROGRAMA & PLAZAS \\
\hline \multirow[t]{3}{*}{ C } & Atención Residencial Básico & 16 \\
\hline & Acogida Inmediata & 13 \\
\hline & Conflicto Social & 10 \\
\hline \multirow[t]{2}{*}{ D } & Atención Residencial Básico & 10 \\
\hline & Discapacidad & 10 \\
\hline E & Atención Residencial Básico & 18 \\
\hline F & Atención Residencial Básico & 18 \\
\hline G & Atención Residencial Básico & 16 \\
\hline $\mathrm{H}$ & Atención Residencial Básico & 10 \\
\hline \multirow[t]{2}{*}{ I } & Integración Social y Laboral & 28 \\
\hline & Problemas de Conducta & 23 \\
\hline $\mathrm{J}$ & Atención Residencial Básico & 10 \\
\hline \multirow[t]{2}{*}{ K } & Alta Intensidad & 12 \\
\hline & Problemas de Conducta & 10 \\
\hline \multirow[t]{3}{*}{$\mathrm{L}$} & Atención Residencial Básico & 59 \\
\hline & Integración Social y Laboral & 16 \\
\hline & Alta Intensidad & 14 \\
\hline M & Alta Intensidad & 5 \\
\hline$\tilde{\mathrm{N}}$ & Alta Intensidad & 6 \\
\hline \multirow[t]{3}{*}{$\mathrm{O}$} & Atención Residencial Básico & 12 \\
\hline & Integración Social y Laboral & 6 \\
\hline & Alta Intensidad & 8 \\
\hline $\mathrm{P}$ & Alta Intensidad & 8 \\
\hline Q & Alta Intensidad & 6 \\
\hline
\end{tabular}

Fuente: elaboración propia a partir de los datos proporcionados por la Delegación Territorial de Educación, Deporte, Igualdad, Políticas Sociales y Conciliación en Almería. 
Para llevar a cabo nuestro estudio utilizamos el muestreo no probabilístico de tipo intencional. Se basa en la intencionalidad que los investigadores han decidido para formar los componentes de la muestra, considerando que son claves para los objetivos del estudio (Ruiz, 2012). Los criterios de inclusión de las personas participantes quedan determinados por ser profesionales en activo de la red institucional de protección de menores y jóvenes (ex)tutelados. Las características de los sujetos se ajustan principalmente a distintas modalidades de programas de protección (Acogida Inmediata, Atención Residencial Básica, Programas de Orientación e Inserción Sociolaboral (POIL) y Alta Intensidad).

Para identificar los sujetos potenciales nos servimos de un profesional educador social y una trabajadora social que desarrollan su trabajo en centros de protección de la capital de Almería (España). Estos profesionales nos ponen en contacto con las personas responsables de distintos centros distribuidos en diferentes puntos geográficos de la provincia de Almería. El procedimiento de contacto para cada centro se desarrolla de la misma forma. Realizamos una primera llamada a la dirección de los centros para acordar una visita para la presentación del estudio. Una vez acordada la fecha, se envía por email la información del trabajo a realizar. En la presentación presencial con el equipo profesional de los centros se contextualiza el estudio, se describen los objetivos y se solicita la petición de participación. Se obtiene así un registro de participantes voluntarios para contactar individualmente la cita de las entrevistas.

Hemos obtenido una muestra total de 30 participantes de siete centros distintos de protección de menores y jóvenes de la provincia de Almería. Cabe indicar que, para la configuración de nuestra muestra final, los informantes de los Centros de atención residencial básica también quedan identificados dentro de los POIL. Esta circunstancia se da en nuestra investigación puesto que dichos profesionales entrevistados estaban asignados en la práctica a los distintos programas.

Se asume que con la muestra obtenida se cubren las posiciones y opiniones de los expertos, alcanzando el grado de saturación en las respuestas.

Las características se describen en la siguiente tabla:

Tabla 2. Características y codificación de informantes.

\begin{tabular}{|c|c|c|c|c|}
\hline $\begin{array}{c}\text { CÓDIGO } \\
\text { INFORMANTE }\end{array}$ & CATEGORÍA PROFESIONAL & SEXO* & ANTIGÜEDAD & TIPO DE CENTRO \\
\hline El & DIRECTORA & $\mathrm{F}$ & 1 a 12 meses & $\begin{array}{l}\text { Centros de Acogida } \\
\text { Inmediata }\end{array}$ \\
\hline E2 & DIRECTORA & $\mathrm{F}$ & 1 a 12 meses & $\begin{array}{l}\text { Centros de Acogida } \\
\text { Inmediata }\end{array}$ \\
\hline E3 & TRABAJADORA SOCIAL & $\mathrm{F}$ & 1 a 12 meses & $\begin{array}{l}\text { Centros de Acogida } \\
\text { Inmediata }\end{array}$ \\
\hline E4 & TRABAJADORA SOCIAL & $\mathrm{F}$ & 1 a 12 meses & $\begin{array}{l}\text { Centros de Acogida } \\
\text { Inmediata }\end{array}$ \\
\hline E5 & TRABAJADORA SOCIAL & $\mathrm{F}$ & 1 a 3 años & $\begin{array}{l}\text { Centros de Acogida } \\
\text { Inmediata }\end{array}$ \\
\hline E6 & TRABAJADORA SOCIAL & $\mathrm{F}$ & +3 años & $\begin{array}{l}\text { Centros de Acogida } \\
\text { Inmediata }\end{array}$ \\
\hline E7 & EDUCADORA SOCIAL & $\mathrm{F}$ & 1 a 12 meses & $\begin{array}{l}\text { Centros de Acogida } \\
\text { Inmediata }\end{array}$ \\
\hline E8 & EDUCADOR SOCIAL & $\mathrm{M}$ & 1 a 12 meses & $\begin{array}{l}\text { Centros de Acogida } \\
\text { Inmediata }\end{array}$ \\
\hline E9 & AUX. TÉC. EDUCATIVO & M & 1 a 12 meses & $\begin{array}{l}\text { Centros de Acogida } \\
\text { Inmediata }\end{array}$ \\
\hline E10 & AUX. TÉC. EDUCATIVO & M & 1 a 12 meses & $\begin{array}{l}\text { Centros de Acogida } \\
\text { Inmediata }\end{array}$ \\
\hline E11 & AUX. TÉC. EDUCATIVO & M & 1 a 12 meses & $\begin{array}{l}\text { Centros de Acogida } \\
\text { Inmediata }\end{array}$ \\
\hline
\end{tabular}




\begin{tabular}{|c|c|c|c|c|}
\hline $\begin{array}{c}\text { CÓDIGO } \\
\text { INFORMANTE }\end{array}$ & CATEGORÍA PROFESIONAL & SEXO* & ANTIGÜEDAD & TIPO DE CENTRO \\
\hline E12 & GOBERNANTA & $\mathrm{F}$ & 1 a 12 meses & $\begin{array}{l}\text { Centros de Acogida } \\
\text { Inmediata }\end{array}$ \\
\hline E13 & TRABAJADORA SOCIAL & $\mathrm{F}$ & +3 años & $\begin{array}{l}\text { Programa de Atención } \\
\text { Residencial Básica/POIL }\end{array}$ \\
\hline E14 & TRABAJADORA SOCIAL & $\mathrm{F}$ & +3 años & $\begin{array}{l}\text { Programa de Atención } \\
\text { Residencial Básica/POIL }\end{array}$ \\
\hline E15 & COORDINADOR & M & +3 años & $\begin{array}{l}\text { Programa de Atención } \\
\text { Residencial Básica/POIL }\end{array}$ \\
\hline E16 & EDUCADORA & $\mathrm{F}$ & +3 años & $\begin{array}{l}\text { Programa de Atención } \\
\text { Residencial Básica/POIL }\end{array}$ \\
\hline E17 & EDUCADORA & $\mathrm{F}$ & +3 años & $\begin{array}{l}\text { Programa de Atención } \\
\text { Residencial Básica/POIL }\end{array}$ \\
\hline E18 & INT. SOCIO-CULTURAL & $\mathrm{F}$ & +3 años & $\begin{array}{l}\text { Programa de Atención } \\
\text { Residencial Básica/POIL }\end{array}$ \\
\hline E19 & TRABAJADORA SOCIAL & F & 1 a 12 meses & Recurso de Alta Intensidad \\
\hline E20 & DIRECTOR & M & +3 años & Recurso de Alta Intensidad \\
\hline E21 & EDUCADOR & M & +3 años & Recurso de Alta Intensidad \\
\hline E22 & PSICÓLOGA & F & +3 años & Recurso de Alta Intensidad \\
\hline E23 & TÉCNICA & F & +3 años & Recurso de Alta Intensidad \\
\hline E24 & EDUCADORA & $\mathrm{F}$ & +3 años & Recurso de Alta Intensidad \\
\hline E25 & TRABAJADOR SOCIAL & M & 1 a 12 meses & Recurso de Alta Intensidad \\
\hline E26 & TÉCNICA & F & 1 a 12 meses & Recurso de Alta Intensidad \\
\hline E27 & TRABAJADORA SOCIAL & F & +3 años & Recurso de Alta Intensidad \\
\hline E28 & EDUCADORA & F & 1 a 12 meses & Recurso de Alta Intensidad \\
\hline E29 & TÉCNICA & M & 1 a 12 meses & Recurso de Alta Intensidad \\
\hline E30 & TRABAJADORA SOCIAL & F & +3 años & Recurso de Alta Intensidad \\
\hline
\end{tabular}

*Sexo. F: femenino - M: masculino

Fuente: Elaboración propia.

\subsection{Procedimiento}

El proceso de recogida de información se realiza de forma individual, en lugares cómodos y confortables para los entrevistados. Se dejó que los informantes seleccionaran el espacio para realizar las entrevistas. Las entrevistas se desarrollaron, principalmente, en despachos propios de los centros o en cafeterías, pero en este último caso intentando que el ruido habitual no interfiriera en dicho proceso de entrevista y recogida de información.

A cada una de las personas entrevistadas se le explicó el propósito de la entrevista, así como el objetivo de la investigación. Se solicitó por escrito el consentimiento expreso para llevar a cabo la entrevista, grabarla en formato de audio, transcribirla y analizarla. El tiempo medio de las entrevistas es de 01:23 (hh:mm), transcurriendo de forma fluida y sin interrupciones significativas.

El proceso de análisis de la información se ha llevado a cabo mediante el software ATLAS.ti
Se realizó una codificación inductiva que nos permitió codificar las ideas y/o conceptos, agrupando la información mediante códigos que se concentraron en dimensiones o subcategorías y estos, a su vez, se agruparon en otras categorías analíticas mayores o centrales.

\section{RESULTADOS Y DISCUSIÓN}

En este apartado queremos poner de manifiesto los resultados obtenidos tras el análisis de las entrevistas. Con el propósito de ofrecer una comprensión general de las opiniones de los/as profesionales entrevistados/ as, se recogen los discursos más representativos. Con ello, los datos que se presentan en este texto congregan principalmente la información emergente de los bloques 4 y 5 del guion de entrevistas.

Estos resultados son comparados con la literatura científica con el objeto de contextualizar, interpretar y enfatizar los datos cualitativos. 
La información de este apartado se desarrolla atendiendo a las distintas codificaciones emergentes, agrupadas en cinco subcategorías y dos categorías centrales o analíticas.

Tabla 3. Sistema de categorías.

\begin{tabular}{|c|c|c|}
\hline $\begin{array}{l}\text { CATEGORIA } \\
\text { ANALÍTICA } \\
\text { O CENTRAL }\end{array}$ & $\begin{array}{l}\text { DIMENSIONES O } \\
\text { SUBCATEGORIAS }\end{array}$ & CÓDIGOS \\
\hline \multirow{6}{*}{$\begin{array}{l}\text { EXPECTATIVAS } \\
\text { DE FUTURO }\end{array}$} & \multirow{3}{*}{ Ámbito laboral } & Formación \\
\hline & & $\begin{array}{l}\text { Regularizar } \\
\text { documentación }\end{array}$ \\
\hline & & $\begin{array}{l}\text { Enviar dinero } \\
\text { a familiares }\end{array}$ \\
\hline & \multirow{3}{*}{ Idealización } & Sueño europeo \\
\hline & & Metas inalcanzables \\
\hline & & $\begin{array}{l}\text { Toma de conciencia } \\
\text { del contexto }\end{array}$ \\
\hline \multirow{12}{*}{$\begin{array}{l}\text { VIVENCIAS SOBRE } \\
\text { LA TRANSICIÓN } \\
\text { HACIA LA VIDA } \\
\text { INDEPENDIENTE: } \\
\text { MANIFESTACIONES } \\
\text { PSICOSOCIALES }\end{array}$} & \multirow{4}{*}{ Mayoría de edad } & Desprotección \\
\hline & & Situación estresante \\
\hline & & $\begin{array}{l}\text { Toma de conciencia } \\
\text { de limitaciones }\end{array}$ \\
\hline & & $\begin{array}{l}\text { Referencias al } \\
\text { sistema familiar }\end{array}$ \\
\hline & \multirow{4}{*}{$\begin{array}{l}\text { Anticipación y } \\
\text { proyección de } \\
\text { la vida como } \\
\text { extutelado }\end{array}$} & $\begin{array}{l}\text { Desprotección } \\
\text { institucional }\end{array}$ \\
\hline & & $\begin{array}{l}\text { Incertidumbre } \\
\text { por el futuro }\end{array}$ \\
\hline & & $\begin{array}{l}\text { Proyecciones } \\
\text { desviadas }\end{array}$ \\
\hline & & $\begin{array}{l}\text { Proyecciones } \\
\text { normalizadas }\end{array}$ \\
\hline & \multirow{4}{*}{$\begin{array}{l}\text { Incumplimiento } \\
\text { de objetivos }\end{array}$} & $\begin{array}{l}\text { Regularizar situación } \\
\text { administrativa }\end{array}$ \\
\hline & & Empleo \\
\hline & & $\begin{array}{l}\text { Comunicación } \\
\text { familiar }\end{array}$ \\
\hline & & $\begin{array}{l}\text { Negativa a volver } \\
\text { al país de origen }\end{array}$ \\
\hline
\end{tabular}

Fuente: Elaboración propia.

\subsection{Sobre las expectativas de futuro}

La categoría central "Expectativas de futuro" nos permite agrupar los elementos, identificados por los profesionales, que influyen o motivan ciertas acciones vitales en los menores.

En este bloque, se recogen citas representativas referentes a las subcategorías "Ámbito laboral" e "Idealización". La dimensión "Ámbito laboral" congrega las referencias codificadas en base a la "formación", "la regularización de la documentación" y el "envío de dinero a familiares". Estos tópicos subrayan el empleo como aspecto nuclear del proyecto vital de los menores. Por otro lado, la subcategoría "idealización" presenta los códigos que se vinculan con aquellas proyecciones que se manifiestan para alcanzar las expectativas. Los aspectos que se identifican se asocian con la configuración del "sueño europeo", las "metas inalcanzables" y la "toma de conciencia del contexto".

\subsection{1. Ámbito laboral}

Los informantes aseveran con rotundidad que la amplia mayoría de los jóvenes sitúan acceder a un trabajo como la meta central en su proyecto de vida. En opinión de los profesionales, la incorporación al mercado de trabajo se entiende como el objetivo vertebrador sobre el cual giran los distintos propósitos que se fijan los jóvenes.

"Encontrar un oficio, un trabajo. Hay chicos que lo demandan desde el principio y hay chicos que te lo demandan al final de su etapa en el Centro, y ese es su mayor objetivo, eso es lo que te dicen, - yo estoy aquí para, primero aprender español, integrarme en la sociedad y encontrar trabajo y formar una familia" (E11).

"La mayoría suelen decir lo mismo, quieran estudiar, quieren conseguir un trabajo, sobre todo que tengan un contrato de trabajo, que puedan quedarse en España" (E7).

"Sí, ellos, sobre todo, bueno, está muy claro que los jóvenes inmigrantes las necesidades que te expresan es que -yo quiero conseguir un trabajo lo antes posible porque necesito ganar dinero, porque tengo que ayudar a mi familia y yo tengo que vivir... y tal-. Ellos necesidad laboral, de sus papeles y trabajo” (E20).

"A nivel de estudiar, no. No viene ninguno con la idea de estudiar más... ¿Qué hay niños que tienen la capacidad? Sí, muchísimos...pero quieren trabajar para mandar dinero a su casa" (E4).

"Ellos quieren trabajar, ellos lo único que demandan es trabajo... ellos lo que quieren es trabajar, lo que demandan es trabajo, sus papeles, que tú les resuelvas su documentación y trabajar, eso es lo que ellos quieren, esas son sus demandas" (E2).

"Ellos demandan sus papeles para trabajar, ya está. A partir de ahí, poco más..." (E3).

"Ellos lo que quieren aqui es trabajar en lo que sea, en lo que puedan y vivir ya está. Es que tampoco piden mucho. La mayoría quieren ayudar a su familia, mandar algo de dinero o no sé yo, supongo que agradecerles un poco el esfuerzo" (E12). 
Se observa que la idea de establecer el trabajo como finalidad del proyecto de vida de los (ex) tutelados coincide con lo manifestado por la literatura científica (Cabedo, 2010, Campos, 2013; Monterde, 2013; Angelidou \& Aguaded, 2016). Se entiende que el estimulo migratorio que impera en los jóvenes viene motivado por mejorar su situación personal y familiar. Para ello, el factor económico resitúa el acceso al empleo como el medio para conseguir los propósitos fijados. Arnau \& Gilligan (2015) inciden en la importancia que tiene para estos jóvenes inmigrantes adquirir un compromiso hacia lo laboral puesto que el trabajo constituye el principal medio para que los extutelados salgan de la situación de exclusión en la que se encuentran ellos y sus familias. Hadjab (2017), advierte que la cuestión laboral no sólo debe entenderse como un factor de prosperidad individualfamiliar, sino que responde a las dinámicas del sistema capitalista del mundo globalizado. La pobreza y la exclusión social se agudiza en origen, incrementando la necesidad de comenzar un proceso migratorio que entraña una realidad muy compleja y violenta. Europa es proyectada como una sociedad respetuosa y rica que, sin embargo, actúa represivamente contra la población inmigrante. El modelo económico imperante crea y utiliza las condiciones de precariedad de la población (in)migrante para generar su propia riqueza.

\subsubsection{Idealización}

Las personas entrevistadas declaran que los menores llegan a los centros con unas aspiraciones poco reales para el contexto de alta complejidad y dificultad en el que viven. En el relato de los profesionales se observa, junto con lo anterior, que la idealización de España, como oportunidad para hacer prosperar la situación de los jóvenes y sus familias, contribuye a reforzar el "sueño europeo" (García, 2016).

\footnotetext{
"Ahora mismo tenemos la Acogida Inmediata de MENAS. Las famosas pateras que llegan al puerto de Almería y que son interceptadas por los Cuerpos y Fuerzas de Seguridad del Estado en el mar de Alborán o en el mediterráneo. Son Subsaharianos y personas del Magreb. Dependiendo de la época del año, predominan más personas del norte de África como Marruecos, Argelia y, también, de subsaharianos esperando en estos países para cruzar a Europa. Estos menores vienen con una idea falsa, pensando que aquí es fácil encontrar trabajo, ganar dinero... pero ellos llegan sin lo más
}

básico...en el centro se les da ayuda inmediata a las necesidades de alimentación, traducción..." (E8).

"... algunos vienen con la perspectiva del sueño europeo, vienen muy confundidos con lo que se van a encontrar porque los inmigrantes que vienen aquí y luego llegan allí con un.... mostrando un éxito alcanzado que... muchísimas veces no es verdad. Es pura apariencia o cosas así y luego se dan unos golpetazos con la realidad" (E2).

"Esto es debido a que muchas veces los chicos llegan a España creyendo algo que no tienen nada que ver con la realidad, porque sus amigos y compatriotas les han vendido una vida que no se corresponde, en muchas veces, a la que realmente están viviendo los que ya están aquí. Es por eso por lo que los chicos llegan con un cúmulo de fantasías y expectativas que nada tiene que ver con lo que aqui existe, con lo que los profesionales ven adecuada mostrarle la realidad tal y como es" (E27).

Estudios como los de Quiroga (2003), Calzada (2007) y Lázaro (2007), apuntaban, hace más de una década, que los proyectos vitales de estos jóvenes estaban fuertemente (re)construidos por la idealización de la realidad que realizaban de EuropaEspaña. Actualmente, trabajos más recientes, siguen señalando ese mismo factor como rasgo reiterativo en los relatos de los procesos migratorios (Hadjab, 2016; Alonso, Santana \& Feliciano, 2018; Nicolae, 2019). Dicha idealización también emerge a la hora de señalar las posibles ocupaciones laborales de los jóvenes extutelados. Los discursos de los profesionales advierten que las expectativas de los jóvenes, a pesar de la claridad a la hora de manifestar el trabajo como eje central en su proyecto de vida, con frecuencia no se ajustan a la realidad.

"Ellos dicen- yo quiero ser...yo quiero trabajar en la NASA-Vienen algunos y te dicen eso. - ¿tú qué formación tienes, qué título tienes? - Entonces, un poco, hay que ir regulándoles y ponerles los pies en el suelo...” (E20).

"Muchos tienen pájaros en la cabeza (...) que creen que van a ser figuras del fútbol, por ejemplo, y venían con esa idea $y$, vamos, no es posible. Ni siquiera pueden llegar a realizar sus sueños en un principio, al menos, porque tienen que estudiar y tienen que trabajar. No pueden dedicarse realmente, a lo mejor, a practicar o a entrenar o... y luego hay otros que, que por muy jóvenes que se crean, con 17 años sabes que realmente no es el jugador que él cree" (E12). 
"Los chicos africanos el fútbol. Vienen engañados totalmente con el fútbol, de que aqui se piensan que aquí en España no hay nadie bueno jugando al fútbol y que los fichadores estos del Madrid y del Barça están esperándolos en la puerta... vienen muy engañados con el fútbol" (E4).

"Ellos quieren ser estrellas de fútbol y les encanta decirlo, $e$ incluso vacilan de que en España nadie sabe jugar al futbol. Tienen metas muy inalcanzables" (E29).

La llegada a España, concretamente a los centros de protección, supone para estos menores una ruptura entre las expectativas que traen y la realidad que se encuentran (Peláez, 2018). Por un lado, los menores infravaloran las dificultades propias del contexto (crisis económica, alta tasa de paro juvenil, escasa oferta de empleo estable, posible rechazo social) y, por otro lado, no son conscientes de las limitaciones de partida (idioma, escasa cualificación), ni del entramado normativo al que deben hacer frente (edad legal para trabajar en España, permiso de trabajo, de residencia, etc.).

"A veces llegan con mucha impaciencia creyendo que el trabajo sale ya, que van a ganar mucho dinero y que va a ser un trabajo muy bueno. Pero la realidad es la que hay. Hay poco trabajo y cuando no tenemos formación y experiencia pues los trabajos son muy limitados. Pero bueno, luego lo van viendo, ellos lo van viendo" (E22).

"Muchos vienen creyéndose que esto es jauja. Entonces, mostrarles realmente que la vida aquí no es fácil para nadie; estamos en un país donde hay una tasa de paro altísimo, donde el mercado laboral es patético y para ellos más, porque no tienen estudios, no tienen idiomas y son los más tendentes a coger los trabajos más precarios” (E2).

"Ya tú tienes que explicarles. -Mira, las cosas son así-. Ellos saben cuál es la realidad. Nosotros les decimos en todo momento cuál es la realidad y lo difícil que está el conseguir ya no sólo los papeles, que está casi imposible, sino la residencia en España" (E9).

"La idea principal es hacerles ver la realidad, pero siempre llevándolos a la motivación, a que es posible conseguir aquello que se propongan. No se trata de hacerles ver todo negro y que caigan en una frustración permanente. Tienen que saber que con esfuerzo, constancia y trabajo podrán conseguir prácticamente todo cuanto se propongan; pero que no es imposible, que se puede hacer. Entonces, cuanto más luche por ello pues más oportunidades tiene" (E21).
"Y realidad, sobre todo, realidad; trabajar y decirles -una vez que salgas, si no vas a un piso, lo vas a tener muy duro-. Entonces, hay que concienciar también a los chicos de que cuando salgan no van a tener nada $y$, a veces, pues o no lo entienden o no sé lo que pasa, pero hay que concienciarlos de la realidad a la que se van a enfrentar una vez que salgan" (E24).

Los profesionales entrevistados consideran como prioritario ofrecer diversas estrategias para que estos menores tomen conciencia de la realidad de su situación. Si bien, las propuestas educativas ofrecidas por las instituciones públicas fijan como objetivo incluir las expectativas y sueños de los jóvenes para trazar los itinerarios socioeducativos (Del Valle \& Quintanal, 2006; Perazzo \& Zuppiroli, 2018), los relatos de los informantes ofrecen una visión más pragmática sobre cómo abordar este conflicto de expectativas. Las personas entrevistadas consideran, por lo general, que es necesario que los jóvenes vean cuanto antes cómo se vive en España, cuáles son las dificultades que existen y qué deben saber antes de que tengan que abandonar el centro de protección.
"nosotros les hemos mostrado asentamientos chabolistas alli al lado de los invernaderos, cuando los llevamos al consulado, y tal y cual, y si nos queda tiempo pues - vamos a pasar por tal sitio, vamos a ver dónde viven a veces vuestros compatriotas- porque se quejan en el centro de la comida, por esto, por lo otro" (E1).
"Sí, es verdad que siempre se intenta hablar con ellos. Es decir, un choque de realidad, ¿qué te vas a encontrar?... intento mucho hablar con ellos; por ejemplo, que una vez que salgan del centro, entre los chicos de aquí, del mismo centro, intenten buscar piso. Intento guiarles de dónde pueden ir a buscar trabajo como Nijar, Roquetas, El Ejido, que allí es donde más trabajo hay..." (E3).

Los resultados evidenciados dentro de esta subcategoría revelan que la idealización constituida por el sueño europeo genera una ruptura entre las expectativas de los menores y la realidad a la que deben enfrentarse. Los proyectos vitales de estos jóvenes no son consecuentes, al menos en los periodos iniciales de llegada a España, con las posibilidades que otorga el país receptor. El equipo educativo de los centros se encarga de minimizar lo antes posible esa distorsión de la realidad. Tal y como señalan Ruiz, Palma \& Vives (2019), consiguientemente, el tratamiento que reciben los menores tutelados suele ser contrario 
a las expectativas, a los intereses y los objetivos que plantearon cuando comenzaron su proceso migratorio.

\subsection{Vivencias sobre la transición hacia la vida independiente: manifestaciones psicosociales}

Este bloque de resultados enuncia aquellos discursos de los profesionales que reflejan cómo viven e interiorizan los menores los procesos derivados de la transición hacia la vida adulta.

La categoría central está compuesta por tres subcategorías. La primera de ellas hace referencia a la "mayoría de edad". En esta dimensión se identifican los códigos "desprotección", "situación estresante", "toma de conciencia de las limitaciones" y "referencias al sistema familiar". En su conjunto, expresan componentes que se (re)construyen en torno a la mayoría de edad.

La segunda subcategoría remite a la "anticipación y proyección de la vida como extutelado". En ella, se consideran las manifestaciones que expresan los profesionales sobre el futuro que tendrán los jóvenes. Los relatos giran en torno a la "desprotección institucional", la "incertidumbre por el futuro", las "proyecciones desviadas" y las "proyecciones normalizadas".

La ultima subcategoría aborda los temas que los profesionales significan y desvelan sobre el "incumplimiento de objetivos" de los menores. Las referencias de los técnicos aluden a la "regularización de la situación administrativa", el "empleo", la "comunicación familiar" y la "negativa a volver al país de origen".

\subsubsection{Sobre la mayoría de edad}

En el momento en el que se produce la transición a la vida adulta de los menores extranjeros tutelados por la administración pública se origina "un salto al vacío, tanto por las circunstancias sociales, laborales y económicas (...), como por la falta de información y evaluación que se ofrece de los programas" (Ruiz et al.: 47). En esta línea, todos nuestros informantes coinciden en aseverar que la mayoría de edad supone el inicio de un estado de desprotección por parte de las administraciones, que es vivido y percibido por los jóvenes como forma de abandono.

"Los de 18 años están en el filo de un abismo, y lo dicen así en los medios..., los dejamos en el precipicio -aquí te dejamos, chaval. Hasta ahora has estado acompañado, hasta los 18, mejor o peor, hasta los 18 ... y ahora, te dejamos en el precipicio y tu verás si te tiras y eres capaz de sobrevivir o te mantienes-. Es decir, hay niños que lo viven muy mal, su mayoría de edad la viven fatal, porque saben que los vamos a abandonar" (E15).

Los profesionales detectan que cumplir la mayoría de edad para los jóvenes tutelados supone una situación estresante caracterizada por un estado generalizado de malestar.

"Sí, sí suelen expresarlo, algunos más que otros, pero sí, suelen expresar ese miedo que tienen por si van a encontrar un trabajo, si no lo van a encontrar...que si mañana ellos pueden ser personas independientes y vivir de manera autónoma... sí, sí que expresan ese miedo" (E20).

"Pues hay chicos que lo viven con verdadera ansiedad. Han estado bajo un sistema de protección durante bastante tiempo. No saben lo que es vivir solos y que ya todo dependa de ellos mismos. Se nota mucho el nerviosismo que tienen las semanas antes de que tengan que irse" (E30).

"Se agobian mucho y lo notas enseguida, cuando te dicen, sin tú decirles nada, - me queda un mes, me quedan dos meses - (...) empiezan a tener inquietudes porque saben que se acerca algo a lo que no saben enfrentarse, a lo que no están preparados, y entonces cuando empiezan a rallarse la cabeza" (E13).

"Tenemos una niña que cumple el año que viene y te dice - ¿y si no cumplo? - yo me quiero quedar en el centro" (E14).

"A mi me han ofrecido hasta pagarnos por quedarse -te puedo pagar y me quedo- no, no...esto no es una residencia universitaria" (E16).

"Son niños que, aunque cumplan la mayoría de edad, no dejan de ser niños (...) y por la desprotección a la que tienen que enfrentarse es normal que les haga sentir inquietos. Es algo desconocido, no saben a qué tendrán que enfrentarse realmente. En el centro están protegidos, saben que no les falta nada y que no les va a pasar nada. Pero en el momento que cumplen la mayoría de edad, todo eso lo pierden y con un futuro incierto, el miedo y la inseguridad se apodera de ellos. Algunos chicos durante su estancia en el centro no suelen mostrar inquietud sobre su posible futuro, pero cuando se acerca la fecha de cumplir la mayoría de edad eso cambia totalmente y, entonces, sí comienzan a preguntar y a sentir esa inquietud de no saber qué va a pasar" (E16). 
Los profesionales entrevistados comparten la idea de que la salida del sistema les produce a los jóvenes sentimientos de inseguridad, soledad y, sobre todo, falta de apoyo. Coincidiendo con diversos estudios en este campo (Montserrat et al., 2011; Hadjab, 2016; Rodríguez García de Cortázar, 2016; Nicolae, 2019; Ortega, 2019), el centro es percibido, en cierto sentido, como un sistema protector estable. En cambio, la mayoría de edad supone una mayor inestabilidad al ser expulsado, de forma general, del sistema de tutela. Esta falta de estabilidad influye para que los jóvenes vivan el proceso de transición de una manera significativamente negativa.

De los relatos de nuestros informantes se extrae que, conforme se aproxima la fecha para alcanzar la mayoría de edad, los jóvenes tutelados son más conscientes de las carencias y dificultades que afrontarán fuera del centro. Estos jóvenes expresan sus preocupaciones por alcanzar aquellos logros que son necesarios para conseguir, con garantías, una emancipación exitosa. Autores como López et al. (2013) recogen la conexión existente entre las dificultades que encuentran los jóvenes extutelados para emanciparse y los problemas emocionales y cambios conductuales que pueden llegar a manifestar.

"Bastante mal, bastante mal. Notas que se ponen muy nerviosos, cuando se acerca el momento, ese en el que ya saben que les queda un mes, ya muy nerviosos, ya preguntan -ipapeles!-. Incluso su actitud cambia. De ver niños que incluso no han sido problemáticos y que llegan a tomar actitudes incluso de reproche (...). Pero es por eso, el nerviosismo que les produce, a ver ahora dónde voy, ahora qué hago" (E9).

"¿Has preguntado?, ¿Has llamado?, ¿Sabemos dónde voy a ir? Y cuando un niño te dice: ¿qué va a pasar conmigo? y no tienes qué decirle... eso es muy duro... lo preguntan así (E12).

"Lo llevan muy mal, muy mal. En el mes de enero, por ejemplo, tuvimos muchas salidas, por lo menos seis o siete menores abandonaron el centro y..., y se notaba en el mismo centro que había un ambiente más..., como más tristón. Siempre hemos sido un centro que..., están siempre de broma y tal y ese mes, pues, fue un poco de bajón para todos, para los maestros y también para ellos" (E8).

"Por ejemplo, la última salida de mayoría de edad que tuvimos se iba a Lorca y era de lo más gritón, de lo más, así como echado para adelante, se te encaraba incluso... yo lo vi llorar el día que lo dejé en la estación de autobuses. O sea que... y eso se notó los dos o tres días antes de que se fuera, era como -no por favor, no dejéis que me vaya, que no me quiero ir- ¿Qué hago yo? De hecho, me pedía, por favor, quedarse más aquí en el centro" (E3).

Las expresiones emocionales de los jóvenes tutelados que deben transitar hacia la vida adulta están vinculadas también por la forma en la que se organiza y percibe el sistema tutelar como extensión de un sistema familiar. Al respecto, los equipos profesionales entrevistados coinciden en señalar que los jóvenes ven el centro de protección como su referencia familiar.
"Desde el principio ellos y a... nosotros tenemos el listado allí en el que todos están avisados y saben cuándo cumple cada uno con el día y vamos trabajando mucho con ellos antes. Pero ellos lo viven mal, porque hay gente que, hay niños que no quieren irse porque también aqui ellos pues tienen su pequeña familia, llevan mucho tiempo los mismos chicos y... pues no quieren irse" (E16).

"Ellos están muy tristes, porque aquí son familia, porque nosotros vamos y venimos. Yo vengo todos los días y muchos fines de semana, vengo un rato los veo, me siento con ellos, pero yo me voy a mi casa y tengo mi vida, pero para ellos esto es su vida, es su casa y para nosotros es un trabajo que lo adoramos y que nos encanta" (E1).

"Durante su proceso en España hasta que cumpla los 18, porque no están solos realmente, están aquí con entre comillas su familia ino?, y a ahora se ven solos, se ven solos con las maletas en la puerta. Aunque siempre intentamos acercarlos y tal ¿no?, pero se ven con las maletas en la puerta y ahora - ¿Dónde voy? ¿Cómo busco trabajo? ¿Cómo busco una casa? ¿Cómo...? - Así que se ponen un poco trastornadillos los pobres” (E3).

"Tienen mucho miedo a no tener nada, el quedarse sin nada, sinfamilia..., sobre todo, los que no tienen familia en España, los que no tienen familia, pues están llorando, no saben dónde van. Nosotros somos su familia" (E4).

Estos discursos ponen de manifiesto el papel central que adquiere el equipo técnico en los centros de protección (Fernández-Ramos, 2019). La investigación doctoral de Rodríguez García de Cortázar (2016) da cuenta del rol que tiene el personal socioeducativo de los centros con relación a las cuestiones como el afecto, el respeto y la comprensión. La postura cercana y afectuosa de los educadores supone el eje central para el bienestar emocional de estos jóvenes. 
Coincidiendo con Fernández \& Cid (2018), los profesionales y menores de los centros se postulan como la principal red de apoyo de los jóvenes durante el proceso de tutela. Esta convivencia hace que los jóvenes tutelados perciban el sistema de protección de menores como un sistema familiar. Así, profesionales y compañeros tutelados se configuran como un capital social significativo del que cuesta desprenderse y emanciparse. Estas vivencias fortalecen el sentimiento de dependencia de los jóvenes hacia el sistema de protección, dejando evidencias de los miedos, inseguridades y preocupaciones sobre las circunstancias en las que estos jóvenes deben abandonar los recursos de protección y tutela.

\subsubsection{Anticipación y proyección de la vida como extutelado}

Se pone de relieve que estos menores al cumplir la mayoría de edad comienzan un proceso que les excluye del régimen de protección. De la misma forma, su situación administrativa podría pasar a una situación irregular a no ser que dispongan o soliciten una autorización de residencia, obtengan su renovación o que hayan adquirido la nacionalidad española.

Las alternativas de protección para los jóvenes que han estado sujetos a la tutela residencial son muy limitadas. Una vez cumplida la mayoría de edad, los casos en los que las autoridades recurren al régimen de la tutela familiar son prácticamente inexistentes. De igual forma, los recursos para la mayoría de edad de tipo residencial, como viviendas tuteladas o asistidas, no dan cobertura a la demanda existente. Las plazas en estos centros son muy escasas y, además, los requisitos de acceso son demasiado rígidos. Esto provoca que en la mayoría de los casos los jóvenes no puedan beneficiarse de tales recursos (Ortega, 2019).

Por último, el retorno con la familia o al país de origen o de procedencia no son, por lo general, las alternativas más adecuadas. Las características del entorno familiar y sus efectos negativos motivan, fundamentalmente, la intención de estos menores a venir a España (Vinaixa, 2019).

\footnotetext{
"Su principal miedo, estar solos, estar solos. Les da mucho miedo la mayoría de edad. Nosotros les damos la posibilidad a todos de que, si quieren volver que nos lo digan, porque podemos... nosotros con el servicio de protección se pone en contacto con los padres y se puede
}

ir con su madre, con una petición de la madre. Pero no quieren" (E4).

"No los aceptan en los recursos de Mayoría de edad, ¡no sé lo que buscan!, un niño modelo que, no sé,... yo tengo niños que llevan 9 meses, que hablan español, que han estado yendo al instituto, que son perfectos $y$ maravillosos, pero, no sé yo qué es lo que buscan para un niño porque... no sé, no entran, ino entran!” (E26).

"Si yo tengo un centro con 25 plazas, y crean uno de mayoría con 4 plazas. A mí hay niños que se me quedan fuera. Que luego hay otro centro con 40 y crean uno con 6. No sé qué quieren que hagamos con el resto, que los colguemos de una percha, que es que no lo entiendo (...). Mucho para Menas pero poco para mayoría. Está descompensado totalmente, no tiene ningún sentido" (E20).

Jariot, Sala \& Arnau (2015), Save the Children (2018), Andalucía Acoge (2019), APDHA (2019), Ortega (2019) evidencian la complejidad de un proceso exitoso de inclusión de los jóvenes extutelados. Entre las circunstancias más significativas se señalan la falta de implicación política, la carencia de recursos, la escasa preparación socioeducativa que alcanzan los menores en los centros y un contexto de inestabilidad económica-laboral con numerosas barreras sociales provocadas por el rechazo extendido hacia la población inmigrante.

"Los extutelados también están recortados, como en todo. Entonces, antes a lo mejor podían aguantarlos hasta no sé, han llegado hasta $4 / 5$ años... un montón de tiempo. Ahora es 1 año lo que te dan de margen, salvo excepciones justificadas. Y no da tiempo a prepararlos para salir. Sólo 1 año... siguen siendo niños. Cumplen 18 años con una madurez que no tienen (...). Tienen pocas posibilidades de inserción laboral porque normalmente sus niveles académicos son bajos; algunos ahora ya salen con la ESO, si tiene suerte alguno se mete en una FP básica o hacer algún módulo de grado medio y tal... pero claro, es muy complicado porque además se ven sin recursos económicamente y dependientes y - a ver cómo lo hago-... Hay gente que ni con 30 se ha ido de su casa de sus padres y nosotros estamos mandando a gente con 19 años a la calle y, además, que se tienen que valer por ellos mismos porque la sociedad no les ayuda". (E13).

Las cuestiones que protagonizan las respuestas de las entrevistas se basan en la preocupación que le genera el futuro de los extutelados. Si bien, existe disparidad en la forma de proyectar el futuro de los 
jóvenes, se observa en el contenido de los discursos una prevalencia significativa hacia una transición a la vida adulta de forma poco exitosa, en términos de inclusión social.

"Pues algunos me los puedo imaginar vendiendo droga en Italia perfectamente; además es la perspectiva que tienen algunos. Dicen que van a acabar...que van a vender droga en Italia... su primo vende y tal... y es así; realmente, estos son carne de cañón también para ese tipo de historias" (E14).

"Me imagino a más de uno en una mafia, así, literal (...) que ellos hablan mucho de eso también como posible salida, como... no es lo que quiero, pero a unas malas, muy malas, muy malas... sé que lo tengo, o sea que por eso me lo imagino a más de uno" (E15).

Los profesionales no desean estas actividades para los jóvenes, pero algunos sí la contemplan como una opción real para cuando salgan del centro. Llevar a cabo actividades ilícitas, pero que le puedan proporcionar a priori una estabilidad económica y un sustento, no es algo que descarten nuestros informantes. García (2016) señala que la nueva realidad de desamparo y desprotección institucional a la que se enfrentan los menores extutelados determina, en algunos casos, la proliferación de alto riesgo delictivo.

Por otro lado, en nuestros resultados también se recogen opiniones de profesionales que identifican modelos de vida para los jóvenes más normalizados y estructurados de acuerdo con los estándares culturales y sociales esperados y aceptados.

"Pues yo me los imagino que al final acabarán quedándose en España y trabajando, encontrando pareja, formando familias, yo creo que sî" (E25).

"Hay chicos que han estado poco tiempo y han aprovechado muy bien, muy bien, y de hecho ahora pues están trabajando, incluso han conseguido traerse a su novia aquí, se han casado, tienen un trabajo estable, son reconocidos en el pueblo o en la zona, los quiere todo el mundo, los conoce todo el mundo... se ha integrado muy bien, porque él ha querido, porque él se ha esforzado, porque es realista" (E19).

"Bueno, ya tenemos jóvenes que estuvieron antes en los pisos o han estado en centros y los estamos viendo, y hay de todo. Hay chicos que aprovechan muy bien el recurso, se ganan su dinerillo para emplearlo en sus familias o se casan, tienen negocios algunos" (E24).
La información aportada por los profesionales significa el aprovechamiento del recurso como factor de garantía para una transición positiva fuera del centro. Los estudios realizados en este ámbito concreto coinciden en señalar como predictores de éxito las experiencias positivas de estos menores en los centros, la motivación, la autoestima académica y laboral y la posibilidad de mantenerse en los recursos una vez cumplido la mayoría de edad (Domínguez, 2012; Vázquez \& Nieto-Morales, 2019).

\subsubsection{Incumplimiento de sus objetivos}

En los discursos de nuestros informantes se asume que los jóvenes extutelados se niegan a volver a su país de origen. Este hecho supondría una evidencia del fracaso de su proyecto migratorio.

"Los chicos no suelen aceptar la propuesta de volver a su país, ya que el llegar hasta aquí ha conllevado de mucho esfuerzo y sacrificio. No solo de él mismo, que es quien ha sufrido el proceso migratorio, sino el compromiso que adquieren para con los padres, ya que suelen ser los que asumen el coste. Ellos te dicen - pues ya, pero es que eso no se puede. Si es que mi madre ha pagado mucho dinero para que yo esté aquí-" (E4).

"Llegar a España requiere de muchos compromisos ocultos. Los chicos no pueden quedar como perdedores, como que no han logrado lo que otros compatriotas si hicieron y, además, con éxito. Tienen el compromiso con los padres y con el entorno, con su sociedad de origen. No pueden volver ya que eso supone un fracaso que no se quieren ni pueden permitirse" (E10).

"Ellos no pueden decir que le ha ido mal nunca. Ellos de cara a los de Marruecos y de cara a su familia van a decir siempre que les ha ido bien, y...se engaña un montón..." (E28).

Palma (2019), en un reciente estudio realizado en Málaga, donde el contexto es similar al de este trabajo, descubre las altísimas reticencias y las negativas de los jóvenes ante la posibilidad de retornar a su país de origen. Señala la autora que la mayoría de los jóvenes extutelados no traslada a sus familias los problemas que encuentran a la hora de avanzar en sus proyectos. Por el contrario, suelen centrarse en los aspectos positivos o, con frecuencia, engañan sobre los objetivos que (no) alcanzan para no preocupar a sus familiares. Los trabajos de Gimeno (2013, 2013b, 2018), con relación a los procesos migratorios y los sistemas de protección de 
menores, nos ayudan a comprender que estos jóvenes, a pesar de vivir experiencias de una fuerte indefensión jurídica y de desamparo institucional, se muestran a sus familias y a su entorno de origen aparentando estabilidad en su proyecto migratorio.

Al respecto, los discursos recogidos en nuestra investigación acreditan que estos hechos son recurrentes, señalando, además, el impacto que provoca el contacto familiar en los jóvenes.

"Yo veo, muchas veces, que la familia los llama para pedirles dinero y los agobian un montón, porque el poco dinero que consiguen o cuando están haciendo prácticas y no tienen dinero. Las familias los presionan para que le envíen dinero, no lo llama para preguntar cómo estas o lo que sea... sino los presionan...-envíame dinero, estoy enferma-, no sé qué. Ellos están aquí los pobres, haciendo todo lo que pueden, matándose a trabajar y a lo mejor... pues no llegan los pobres y prefieren, a lo mejor, quedarse ellos sin nada para mandarles el dinero al familiar" (E22).

"Sí, sí, sobre todo los que vienen de fuera pues está el tema de la familia, que les presionan para que les envíen dinero, es muy agobiante eso; que tú estés aquí luchando, esforzándote y la familia presionando y encima a lo mejor les dicen -pues no sé quién está enfermo- con lo cual, puede ser verdad o mentira, pero les meten mucha más presión" (E26).

Los profesionales entrevistados exteriorizan la importancia de la familia como anclaje del proceso migratorio. Como se ha visto, las condiciones socioeconómicas que atraviesan la familia en sus países de origen motivan, principalmente, la decisión de iniciar el proceso migratorio. Dicho proceso se realiza apoyado por el entorno próximo de los menores.

Tal y como refleja Rodríguez García de Cortázar (2016), la migración no siempre supone un movimiento deseado. Dicho proceso es consecuencia, fundamentalmente, de la situación del país de origen. Por ello, la consecución de ciertos objetivos materiales tampoco sustituye la ausencia de sus referentes familiares y la carencia de los afectos que pudieran tener estos menores.

Autores como Markez \& Pastor (2010), Martínez \& Martínez (2018) también describen, tal y como se pone de manifiesto en los discursos recogidos en nuestra investigación, que los menores y extutelados experimentan incertidumbres, emociones negativas y dificultades para alcanzar el objetivo económico. La familia desempeña, desde ese momento, un doble rol. Por un lado, se comporta como sustento emocional que refuerza la vinculación afectiva, a pesar de la distancia física ente los lugares de origen y destino; por otro, la relación entre familiares y (ex)tutelados se convierte en un vehículo de trasmisión de vivencias encarnadas por estas familias que contribuyen a que los jóvenes terminen experimentando sentimientos ambivalentes. La presión que ejercen las familias no es idónea para que estos jóvenes puedan expresar su malestar dentro de un escenario de ventilación emocional.

\section{CONCLUSIONES}

Las experiencias de los profesionales de los centros de acogida residencial, que se han analizado para este trabajo, nos permiten extraer algunas conclusiones que impactan en la práctica del sistema público de protección de estos menores y de los extutelados.

Es evidente que el proceso migratorio de los menores se desarrolla con la finalidad principal de mejorar la situación familiar en el país de origen. Este estímulo migratorio se proyecta en la idea central que tienen los menores tutelados de acceder a un empleo estable como instrumento para estructurar su proyecto de vida. Los jóvenes manifiestan el trabajo como eje central; sin embargo, sus expectativas no se ajustan a la realidad.

Se evidencia una idealización de España como oportunidad para hacer prosperar la situación de los jóvenes y sus familias que contribuye a reforzar el "sueño europeo". Por ello, los profesionales utilizan una propuesta práctica basada en la toma de conciencia de los menores sobre la realidad de su situación. Los técnicos muestran presencialmente a los tutelados las situaciones de vulnerabilidad, precariedad y exclusión en las que conviven muchos inmigrantes adultos que llegaron a España en condiciones similares. El equipo profesional busca, con esto, minimizar la distorsión entre las expectativas de los menores y los objetivos reales que puedan definirse.

En lo referente a la transición hacia la vida adulta, los menores extranjeros tutelados por la administración pública comparten la idea de que la salida del sistema les produce sentimientos de inseguridad, soledad y, sobre todo, falta de apoyo. Los 
profesionales denuncian una total desprotección del sistema al cumplir los 18 años. Esta toma de conciencia por parte de los menores impacta negativamente en los proyectos educativos, en las actitudes y comportamientos, así como a la hora de reconfigurar su futuro. El desamparo que sufrirán los jóvenes extutelados anticipa las oportunidades de desarrollo personal de estos jóvenes, incluso siendo menores tutelados. En la medida que los menores se acercan a la mayoría de edad se visibilizan comportamientos más disruptivos y expresiones psicológicas de carácter negativo. De ahí se detecta la necesidad de prevenir los posibles riesgos. La oportunidad de estos jóvenes de tener garantizada una cobertura protectora a nivel legal (situación administrativa), social (recursos tras la mayoría de edad) y económica (mediante la garantía de ingresos incondicionales) constituyen, en sí mismos, mecanismos de prevención e intervención de los menores tutelados.

La proyección de futuro de alto riesgo social que advierten los profesionales para los jóvenes extutelados justifica la necesidad de cuestionar el modelo de protección de tutela; además de actuar con rigurosidad ante las evidencias que ofrece la experiencia profesional.

De otra parte, en este artículo también se hace necesario reflexionar sobre la forma en la que los profesionales reconocen, construyen y presentan los procesos que protagonizan los menores. Siguiendo a Jiménez \& Trujillo (2019), la participación como usuarios del sistema público de protección de los menores que migran de forma autónoma impulsa la preocupación de los profesionales sobre determinados aspectos interculturales. Los discursos sobre los procesos migratorios, las expectativas, los objetivos alcanzables, las vivencias de los menores en los centros y la propia intervención profesional quedan atravesados por condiciones sociales, políticas, económicas, culturales y religiosas que están circunscritas a cuestiones interculturales. Sin embargo, se impone una construcción etnocéntrica de la realidad. Por un lado, se significa al menor que migra como parte de una otredad. Se videncia no solo en la configuración del discurso, mediante las referencias a ellos y nosotros, sino en la manera en la que se organizan, diseñan y desarrollan las intervenciones de los profesionales. En consecuencia, se utiliza la noción de territorialidad para describir un funcionamiento social aceptable. El sistema social occidental y europeo no se cuestiona, sino que se utiliza como marco de integración de los menores. Por el contrario, el sistema social de procedencia es percibido como amenazante, en tanto que conforma un conjunto de prácticas culturales que dificultan la consecución de los objetivos deseables en el país de acogida.

La caracterización de otredad también se manifiesta en la distinción entre los menores extranjeros no acompañados y los menores del grupo de referencia (autóctonos). Esta diferenciación no implica en todos los casos una mirada despreciativa hacia los menores extranjeros, pero de cualquier modo sí refleja las distintas exigencias que se piden a unos y otros para el cumplimiento de los objetivos socialmente establecidos.

En consecuencia, los profesionales tienden a nombrar a los menores extranjeros no acompañados desde la homogeneidad grupal. Se les significa como colectivo que comparte realidades y situaciones. Ciertamente, los técnicos describen aspectos diferentes entre los individuos a la hora de relatar algunas vivencias, pero en el conjunto de los discursos la emigración y los aspectos culturales constituyen el principal referente de identificación de los menores.

La invisibilidad de la heterogeneidad del colectivo tiene una serie de implicaciones para las biografías particulares de los menores que conviven en el país de destino. Las políticas públicas, la red de protección, la intervención socioeducativa, el rechazo o la aceptación de la sociedad quedan constreñidas a las representaciones sociales que se construyen en torno al imaginario colectivo. Estos menores están expuestos a situaciones de especial vulnerabilidad e incertidumbre, en mayor medida, por ser categorizados como menores y jóvenes inmigrantes. Estas categorías no son neutras, sino que contienen un potencial jurídico, simbólico e instrumental que (de)limita sus condiciones de vida (Quiroga \& Sòria, 2010; Senovilla, 2014).

Este planteamiento sugiere la necesidad de desplazar el foco de la atención, centrado, principalmente, en las propiedades fronterizas de las migraciones. Las características colectivas de esta realidad deben (re)situarse desde la condición de menores. Esta concepción, aunque tampoco es unívoca, devuelve un significado que fue despojado al iniciar el proceso migratorio (Monteros, 2019). 
A partir de ahí, se necesita dotar de mayor protagonismo las realidades y necesidades individuales experimentadas desde las experiencias encarnadas. El reto que se demanda no es otro sino el de constituir, para estos jóvenes, un proceso de emancipación sustentado en la condición de ciudadanía; que les ha sido quebrantada al comenzar un proceso de cosificación institucional (Rodríguez García de Cortázar \& Gimeno, 2018).

Para avanzar en este marco de investigación, es necesario reflejar algunas de las principales limitaciones de este trabajo. En este sentido, el tamaño y las características de los participantes suponen un inconveniente para proyectar los datos obtenidos como resultados generales y generalizados. Además, para explorar con mayor alcance este fenómeno, se debe tener en cuenta la inclusión expresa de los discursos de los menores y jóvenes extutelados en tanto que son los protagonistas de esta realidad.

No obstante, el análisis comparado de las publicaciones en esta área temática, así como los discursos de los agentes implicados, suscitan la pertinencia de proponer mejores alternativas para la transición de estos menores a la mayoría de edad.

Esta investigación ofrece nuevas evidencias que dan cuenta de los desafíos pendientes que quedan por abordar. Los resultados obtenidos en este trabajo nos orientan hacia el rediseño de las políticas de protección de los menores tutelados como propuesta glocalizada.

Además, entendemos que los futuros estudios en este campo, así como el rediseño de las medidas institucionales de cobertura pública, suponen un reto ineludible para hacer frente a la crisis social derivada de la pandemia de COVID-19.

\section{REFERENCIAS BIBLIOGRÁFICAS}

Alonso, E., Santana, E., \& Feliciano, L. (2018). Trayectorias de empleabilidad de los jóvenes que abandonan el sistema de protección. Educatio Siglo XXI, 36(3), 485-504. http://dx.doi.org/10.6018/j/350101

Ameigeiras, A. R. (2009). El abordaje etnográfico en la investigación social. En I. Vasilachis (coord.), Estrategias de investigación cualitativa (pp. 107-152). Barcelona: Gedisa.

Andalucía Acoge. (2019). Desprotección de la infancia en la Frontera Sur. Menores sin referentes familiares y juventud extutelada en Andalucía, Ceuta y Melilla.
Federación Andalucía Acoge.

Angelidou, G., \& Aguaded, E. (2016). Los derechos de los menores extranjeros no acompañados en los centros de menores. Revista Internacional de Didáctica y Organización Educativa, (2), 4-20.

Aparicio, L. (2015). Avances y desafíos en la regulación de los menores extranjeros no acompañados en España. Revista Boliviana de Derecho, 20, 120-141. Recuperado el 12 de noviembre de 2020, de http://www.revista-rbd. com/articulos/2015/120-141.pdf

APDHA. (2006). Menores extranjeros no acompañados en Andalucía. Entre la represión y la protección. Asociación pro derechos humanos de Andalucía. Recuperado el 12 de noviembre de 2020, de informemena0606.pdf

http://www.apdha.org/webanterior/media/

APDHA. (2019). Infancia migrante. Derechos Humanos en la Frontera Sur 2019. Recuperado el 14 de noviembre de 2020, de https://www.apdha.org/informe-infanciamigrante/

Arnau-Sabatés, L., \& Gilligan, R. (2015). What helps young care leavers to enter the world of work? Possible lessons learned from an exploratory study in Ireland and Catalonia. Children and Youth Services Review, 53, 185-191. https://doi.org/10.1016/j.childyouth.2015.03.027

Bargach, A. (2009). La integración del menor migrante sin referente adulto en el país receptor. En A.S. Jiménez (coord..), Menores migrantes sin referentes familiares: una perspectiva integral del fenómeno (pp. 29-34). Granada: Grupo Editorial Universitario.

Cabedo, V. (2010). La situación de los menores inmigrantes no acompañados. Su protección e integración. Valencia: Tirant lo Blanch.

Cabedo, V., \& Cloquell, A. (2012). Los menores extranjeros no acompañados en los sistemas de protección a la infancia de las Comunidades Autónomas. Valencia: Tirant lo Blanch.

Calzada, O. (2007). La protección de los menores extranjeros no acompañados en Cantabria. Cantabria: Dirección General de Políticas Sociales.

Campos, G. (2013). Transición a la vida adulta de los jóvenes acogidos en residencias de protección. Tesis doctoral, Universidad Autónoma de Madrid. Recuperado el 31 de marzo de 2020, de https://repositorio.uam.es/ handle/10486/13014

Casas, F., \& Monserrat, C. (2009). Sistema educativo e igualdad de oportunidades entre los jóvenes tutelados: estudios recientes en el Reino Unido. Psicothema, 21(4), 543-547. Recuperado el 31 de marzo de 2020, de http:// www.psicothema.es/pdf/3668.pdf

Defensor del Menor de Andalucía (2020). Informe Anual 2019. Sevilla: Defensor del Menor de Andalucía.

Del Valle, J.F. (1998). Y después... ¿qué? Estudio de casos que fueron acogidos en residencias de protección de menores en el Principado de Asturias. Oviedo: Consejería de Servicios Sociales del principado de Asturias.

Del Valle, J. F. (2006). El acogimiento residencial en la protección a la infancia. En M.I. Hombrados, M.A. García y T. López (Eds.), Intervención social y comunitaria. (pp. 241-250). 
Málaga: Ediciones Aljibe.

Del Valle, J. F. (2008). Spain. En M. Stein, H. Ward y E. Munroe (Eds.), Young People's Transitions from Care to Adulthood. International Re-search and Practice. (pp. 173184). London: Jessica Kingsley.

Del Valle, J. F., \& Quintanal, J. (2006). Umbrella, habilidades para la vida. Oviedo: ASACI.

Domínguez, FJ. (2012). ¿Hacia dónde va el acogimiento residencial? International Journal of Developmental and Educational Psychology INFAD, 1 (1), 141-150. Recuperado el 31 de marzo de 2020, de http://hdl. handle.net/10662/2556

Durán, FJ. (2019). El sistema de protección de la infancia y la adolescencia en España y los menores extranjeros no acompañados: reformas, insuficiencias y contradicciones. En F. J. Durán y R. Martínez (Dir.), Migrantes menores y juventud migrante en España y en Italia (pp. 31-58). Granada: Comares.

Escobar, J., \& Cuervo, A. (2008). Validez de contenido y juicio de expertos: una aproximación a su utilización. Avances en medición, 6(1), 27-36

Fernández-Ramos, M. V. (2019). Niños y niñas no acompañados. Entre la desprotección y la garantía de derechos. Trabajo Social, 21(2), 118-139. https://doi. org/10.15446/ts.v21n2.75262

Fernández, D., \& Cid, X. (2017). Análisis longitudinal de la transición a la vida adulta de las personas segregadas del sistema de protección a la infancia y a la adolescencia. Borbón. Revista de Pedagogía, 70(2), 25-38. https://doi. org/10.13042/Bordon.2018.54539

Fiscalía General del Estado (2019). Memoria Anual.2018. Madrid: Fiscalía General del Estado. Ministerio de Justicia. Recuperado el 30 de marzo de 2020, de https:// www.fiscal.es/memorias/memoria2019/FISCALIA_SITE/ index.html

García-Barriocanal, C., Imaña, A., \& De la Herrán, A. (2007). El Acogimiento Residencial como Medida de Protección al Menor. Madrid: Defensor del Menor en la Comunidad de Madrid.

García, E. (2016). De menores inmigrantes en protección a jóvenes extranjeros en prisión. Indret: Revista para el Análisis del Derecho, 3, 1-27.

Gimeno, C. (2013). Trabajo Social y control migratorio. Tensiones en los sistemas de protección de menores. Portularia, XIII (2), 15-25. http://dx.doi.org/10.5218/ prts.2013.0014

Gimeno, C. (2013b). Expectativas de acogida en el imaginario de los menores que migran solos. Revista Electrónica de Investigación y Docencia, 9, 142-158. Recuperado el 18 de marzo de 2020, de https://redib.org/Record/oai_ articulo1324264

Gimeno, C. (2018). Retos de la acogida residencial a menores que migran solos: hacia un Trabajo Social transnacional. Cuadernos de Trabajo Social, 31(1), 95-108. https://doi. org/10.5209/CUTS.56005

Hadjab, H. (2017). Las nuevas generaciones de personas menores migrantes. Tesis doctoral, Universidad de Granada. Recuperado el 22 de noviembre de 2020, de https:// digibug.ugr.es/handle/10481/45098

Inglés, A. (Dir.) (2005). Aprendiendo a volar. Estudio para el análisis de los programas europeos Mentor 15 y Ulises dedicados al proceso de socialización de adolescentes y jóvenes tutelados que han alcanzado la mayoría de edad o están cerca de ella. Murcia/España: Fundación Diagrama

Jariot, M., Parrón, M. R., Roca, J. S., \& Villalba, A. (2008). El proceso de desinternamiento de jóvenes ex tutelados para favorecer una inserción sociolaboral positiva: análisis de la situación actual en los centros residenciales de acción educativa de Cataluña. Bordón. Revista de pedagogía, 60(3), 49-66. Recuperado el 31 de marzo de 2020, de https://recyt.fecyt.es/index.php/BORDON/ article/view/29000

Jariot, M., Sala, J., \& Arnau, L. (2015). Jóvenes tutelados y transición a la vida independiente: indicadores de éxito. REOP - Revista Española de Orientación y Psicopedagogía, 26(2), 90-103. Recuperado el 31marzo de 2020, de http:// revistas.uned.es/index.php/reop/article/view/15218

Jiménez, M. (2003). Buscarse la vida. Análisis trasnacional de los procesos migratorios de los menores marroquies no acompañados en Andalucía. Madrid: Ediciones SM. Fundación Santa María.

Jiménez, M. (2011). Intrusos en la fortaleza. Menores marroquíes migrantes en la Frontera Sur de Europa. Tesis doctoral, Universidad Autónoma de Madrid. Recuperado el 31 de marzo de 2020, de https://repositorio.uam.es/xmlui/ handle/10486/6842

Jiménez, M., \& Trujillo, M.A. (2019). Infancia, adolescencia y juventud extranjeras que migran de forma autónoma. Entre la agencia, las movilidades y las fronteras. Revista Arxiu d'Etnografia de Catalunya, 20, 183-204.

https://doi.org/10.17345/aec20.183-204

Junta de Andalucía (2020). Acogimiento residencial en centros de protección de menores. Recuperado el 18 de abril de 2020, de https://www.juntadeandalucia. es/organismos/igualdadpoliticassocialesyconciliacion/ areas/infancia-familias/separacion-familia/paginas/ acogimiento-residencial.html

Lázaro, I. (2007). Menores Extranjeros No Acompañados: la situación en España. Prolegómenos. Derechos y Valores de la Facultad de Derecho, 10(19), 149-162.

López, M., Santos, I., Bravo, A., \& Del Valle, J. (2013). El proceso de transición a la vida adulta de jóvenes acogidos en el sistema de protección infantil. Revista Anales de psicología, 29(1), 187-196. http://dx.doi.org/10.6018/ analesps.29.1.130542.

Markez, I., \& Pastor, F. (2010). Menores Extranjeros No acompañados (MENA), un colectivo especialmente vulnerable ante las drogas. Zerbitzuan. Revista de servicios sociales, 48, 71-85. Recuperado el 17 de abril de 2020, de https://dialnet.unirioja.es/servlet/ articulo? codigo $=3419593$

Martínez, M., \& Martínez, J. (2018). Procesos migratorios e intervención psicosocial. Papeles del Psicólogo, 39(2), 96103. https://doi.org/10.23923/pap.psicol2018.2865

Melendro, M. (Dir.) (2007). Estrategias educativas con adolescentes y jóvenes en dificultad social. El tránsito a la vida 
adulta en una sociedad sostenible. Madrid: UNED.

Monterde, C. G. (2013). Expectativas de acogida en el imaginario de los menores que migran solos. Revista electrónica de Investigación y Docencia (REID), 9, 142-158.

Monteros, S. (2019). El sujeto de la agencia en las trayectorias vitales de niños marroquíes migrantes: tejiendo historias de alienación y separación con las estructuras de reproducción social. Revista THEOMAI. Estudios críticos sobre Sociedad y Desarrollo, 40, 34-50. Recuperado el 20 de noviembre de 2020, de http://revista-theomai.unq. edu.ar/NUMERO_40/3.\%20Obelar_40.pdf

Montesino, N. (2015). Reflexiones sobre movilidades infantiles desde Marruecos a Suecia. En J. García, A. Megías y J. Ortega (Eds.), VIII Congreso Migraciones Internacionales en España. S.18 (pp. 209-219). Granada: Universidad de Granada.

Montserrat, C., Casas, F., Malo, S., \& Bertran, I. (2011). Los itinerarios educativos de los jóvenes extutelados. Madrid: Ministerio de Sanidad, Política Social e Igualdad. Centro de publicaciones. Recuperado el 12 de abril de 2020, de http://www.observatoriodelainfancia.mscbs.gob.es/ productos/pdf/UCI2011.pdf

Nicolae, A. G. (2019). Predicción afectiva en el proceso migratorio de menores y jóvenes extranjeros no acompañados en acogida y emancipación. Tesis doctoral, Universidad del País Vasco. Recuperado el 15 de noviembre de 2020, de https://addi. ehu.es/handle/10810/33243

Ortega, J. (2019). De menor migrante a joven extutelado/a: Los retos en el proceso de transición hacia la mayoría de edad. El caso de la Comunidad Autónoma de Andalucía. Tesis doctoral, Universidad de Granada. Recuperado el 16 de noviembre de 2020, de http://hdl.handle.net/10481/56015

Palma, de las Olas M. (2019). Joven-ex. La realidad de los jóvenes extutelados en la ciudad de Málaga. Informe final. Málaga: Ayuntamiento de Málaga. Recuperado el 18 de abril de 2020, de

http://observatoriosocial.malaga.eu/opencms/export/sites/ observasocial/.content/galerias/documentos/Joven-ex_ INFORME_FINAL.pdf

Peláez, P. (2018). Estado de la cuestión sobre los derechos de los MENAS en España: entre la protección y el abandono. RES, Revista de Educación Social, 27, 48-70. Recuperado el 30 de marzo de 2020, de http://www.eduso.net/res/ winarcdoc.php?id=1158

Perazzo, C., \& Zuppiroli, J. (2018). Los más solos. Fallos en el sistema de acogida, protección e integración de los menores migrantes no acompañados que llegan a España. España: Save the Children. Recuperado el 30 de marzo de 2020, de https://www.savethechildren.es/sites/default/files/ imce/los_mas_solos_vok.pdf

Quiroga, V. (2003). Els petits "Harraga" menors immigrants irregulars no acompanyats d'origen marroquí a Catalunya. Tesis doctoral, Universitat Rovira i Virgili. Recuperado el 15 de noviembre de 2020, de http://hdl.handle. net/10803/8417

Quiroga, V., \& Soria, M. (2010). Los y las menores migrantes no acompañados/as. Entre la indiferencia y la invisibilidad. Educación social: Revista de intervención socioeducativa, 45, 13-35. Recuperado el 20 de noviembre, de https://www.raco.cat/index.php/ EducacioSocial/article/view/208579/369359

Rodríguez García de Cortázar, A. (2016). Chicos marroquíes buscando su futuro: La experiencia de migrar, entre la violencia estructural y las violencias cotidianas. Tesis doctoral, Universidad de Granada. Recuperado el 24 de noviembre de 2020, de http://hdl.handle.net/10481/43017

Rodríguez García de Cortázar, A., \& Gimeno, C. (2018). Acercarse a las migraciones juveniles e infantiles. En A. Rodríguez García de Cortázar y C. Gimeno (Coords.), Las migraciones de jóvenes y adolescentes no acompañados. Una mirada internacional (pp. 13-22). Granada: Universidad de Granada.

Ruiz, A.C., Palama, M.O., \& Vives, L.C. (2019). Jóvenes inmigrantes extutelados. El tránsito a la vida adulta de los menores extranjeros no acompañados en el caso español. Ehquidad Internacional Welfare Policies and Social Work Journal, 12, 31-52. https://doi.org/10.15257/ ehquidad.2019.0009

Ruiz, J. I. (2012). Metodología de la investigación cualitativa. Bilbao: Universidad de Deusto.

Sala-Roca, J., Villalba, A., Jariot, M., \& Rodríguez, M. (2009). Characteristics and sociolabour insertion of young people after residential foster. International Journal of Child y Family Welfare, 12(1), 22-34. Recuperado el 30 de marzo de 2020, de http://grupsderecerca.uab.cat/iars/ en/content/characteristics-and-sociolabour-insertionyoung-people-after-residential-foster

Sala-Roca, J., Villalba, A., Jariot, M., \& Arnau, L. (2012). Socialization process and social support networks of out-of-care youngsters. Children and Youth Services Review, 34(5), 1015-1023. https://doi.org/10.1016/j. childyouth.2012.02.002

Save the Children. (2018). Los más solos. Los fallos en el sistema de acogida, protección e integración de los menores migrantes no acompañados que llegan a España. Save the Children España. Recuperado el 12 de noviembre de 2020, https://www.savethechildren.es/sites/default/files/imce/ los_mas_solos_vok.pdf

Senovilla, D. (2014). Analyse d'une catégorie juridique récente: le mineur étranger non accompagné, séparé ou isolé. Revue Européenne des Migrations Internationales, 30 , 17-34. https://doi.org/10.4000/remi.6732

Strauss, A. L., \& Corbin, J. (2012). Bases de la investigación cualitativa: técnicas y procedimientos para desarrollar la teoría fundamentada. Medellín: Universidad de Antioquía.

Taylor, S. J., \& Bogdan, R. (2010). Introducción a los métodos cualitativos de investigación: la búsqueda de significados. Barcelona: Paidós.

Valles, M. S. (2009). Técnicas cualitativas de investigación social: reflexión metodológica y práctica profesional. Madrid: Síntesis.

Vasilachis, I. (2009). La investigación cualitativa. En I. Vasilachis (coord.), Estrategias de investigación cualitativa (pp. 23-64). Barcelona: Gedisa.

Vázquez, M. J., \& Nieto-Morales, C. (2019). Los menores no acompañados (MENA) desde el país de origen hasta su 
inserción sociolaboral en destino: claves metodológicas de una efectiva integración social. En M. E. Nieto y C. Nieto (coord.), Personas con necesidades de oportunidades. Una perspectiva práctica (pp. 215- 230). Madrid: Dykinson.

Vinaixa, M. (2019). La mayoría de edad: un mal sueño para menores extranjeros no acompañados. Cuadernos de Derecho Transnacional, 11(1), 571-602. https://doi. org/10.20318/cdt.2019.4633

\section{NOTAS BIOGRÁFICAS}

\section{ISABEL MARÍA MARTÍNEZ SALVADOR}

Doctora por la Universidad de Almería. Máster Oficial en Estudios e intervención social en inmigración, desarrollo y grupos vulnerables. Licenciada en Ciencias del Trabajo, Diplomada en Trabajo Social y Diplomada en Relaciones Laborales. Profesora Sustituta Interina del Área de Trabajo Social y Servicios Sociales en la Universidad de Almería.

\section{JESÚS MUYOR RODRÍGUEZ}

Doctor por la Universidad de Jaén (España) y profesor del Área de Trabajo Social y Servicios Sociales de la Universidad de Almería.

Como investigador es colaborador del Centro de Investigación para el Estudio de las Migraciones y las Relaciones Interculturales (CEMyRI) y miembro del Grupo de investigación SEJ-419, Sección de Sociología, de la Universidad de Almería. Sus intereses se centran en las políticas sociales, los servicios sociales y los grupos vulnerables.

\section{ROCÍO LÓPEZ SAN LUÍS}

Doctora en Derecho por la Universidad de Almería y Profesora Titular de Derecho civil. Docente en la citada Universidad desde el año 1998. Sus líneas de investigación se centran en el Derecho de familia, protección de la infancia y la adolescencia y la mediación familiar. Forma parte de diversos proyectos de investigación relacionados con sus líneas investigadoras, y es miembro del grupo de investigación "Estudios de Derecho privado y comparado" (SEJ-560). 
